NASA/TM-2011-217096

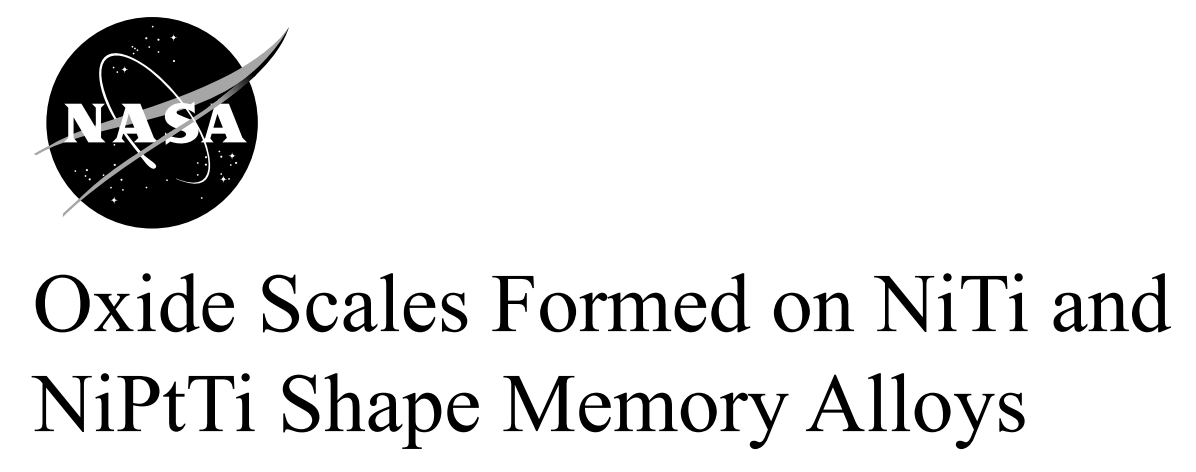

James L. Smialek, Anita Garg, Richard B. Rogers, and Ronald D. Noebe Glenn Research Center, Cleveland, Ohio 


\section{NASA STI Program . . . in Profile}

Since its founding, NASA has been dedicated to the advancement of aeronautics and space science. The NASA Scientific and Technical Information (STI) program plays a key part in helping NASA maintain this important role.

The NASA STI Program operates under the auspices of the Agency Chief Information Officer. It collects, organizes, provides for archiving, and disseminates NASA's STI. The NASA STI program provides access to the NASA Aeronautics and Space Database and its public interface, the NASA Technical Reports Server, thus providing one of the largest collections of aeronautical and space science STI in the world. Results are published in both non-NASA channels and by NASA in the NASA STI Report Series, which includes the following report types:

- TECHNICAL PUBLICATION. Reports of completed research or a major significant phase of research that present the results of NASA programs and include extensive data or theoretical analysis. Includes compilations of significant scientific and technical data and information deemed to be of continuing reference value. NASA counterpart of peer-reviewed formal professional papers but has less stringent limitations on manuscript length and extent of graphic presentations.

- TECHNICAL MEMORANDUM. Scientific and technical findings that are preliminary or of specialized interest, e.g., quick release reports, working papers, and bibliographies that contain minimal annotation. Does not contain extensive analysis.

- CONTRACTOR REPORT. Scientific and technical findings by NASA-sponsored contractors and grantees.
- CONFERENCE PUBLICATION. Collected papers from scientific and technical conferences, symposia, seminars, or other meetings sponsored or cosponsored by NASA.

- SPECIAL PUBLICATION. Scientific, technical, or historical information from NASA programs, projects, and missions, often concerned with subjects having substantial public interest.

- TECHNICAL TRANSLATION. Englishlanguage translations of foreign scientific and technical material pertinent to NASA's mission.

Specialized services also include creating custom thesauri, building customized databases, organizing and publishing research results.

For more information about the NASA STI program, see the following:

- Access the NASA STI program home page at http://www.sti.nasa.gov

- E-mail your question via the Internet to help@ sti.nasa.gov

- Fax your question to the NASA STI Help Desk at $443-757-5803$

- Telephone the NASA STI Help Desk at 443-757-5802

- Write to: NASA Center for AeroSpace Information (CASI) 7115 Standard Drive Hanover, MD 21076-1320 
NASA/TM-2011-217096

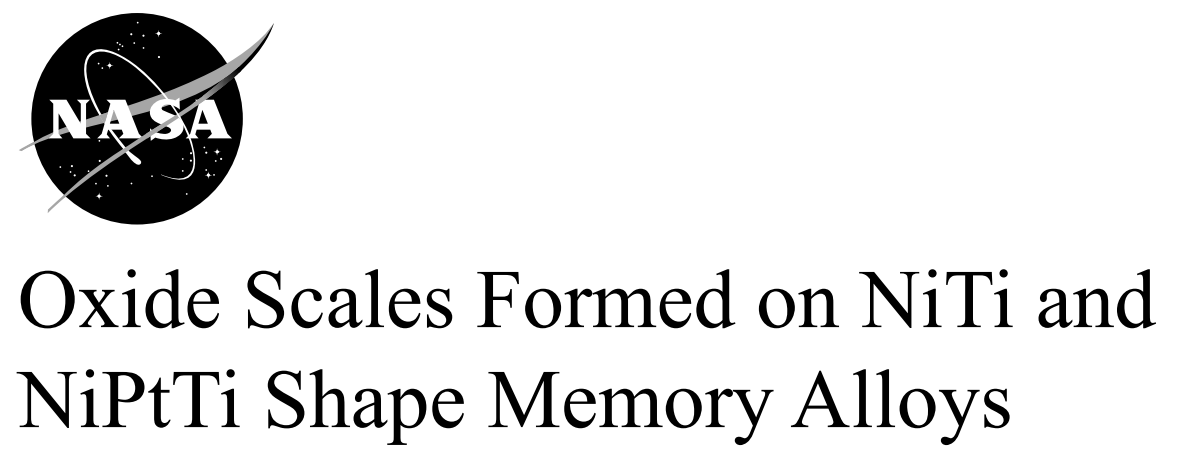

James L. Smialek, Anita Garg, Richard B. Rogers, and Ronald D. Noebe Glenn Research Center, Cleveland, Ohio

National Aeronautics and

Space Administration

Glenn Research Center

Cleveland, Ohio 44135 


\section{Acknowledgments}

The authors thank R. Mattingly for assistance with XRD data acquisition and analysis.

Trade names and trademarks are used in this report for identification only. Their usage does not constitute an official endorsement, either expressed or implied, by the National Aeronautics and Space Administration.

This work was sponsored by the Fundamental Aeronautics Program at the NASA Glenn Research Center.

Level of Review: This material has been technically reviewed by technical management.

Available from

NASA Center for Aerospace Information 7115 Standard Drive

Hanover, MD 21076-1320
National Technical Information Service 5301 Shawnee Road Alexandria, VA 22312

Available electronically at http://www.sti.nasa.gov 


\title{
Oxide Scales Formed on NiTi and NiPtTi Shape Memory Alloys
}

\author{
James L. Smialek, Anita Garg, Richard B. Rogers, and Ronald D. Noebe \\ National Aeronautics and Space Administration \\ Glenn Research Center \\ Cleveland, Ohio 44135
}

\begin{abstract}
$\mathrm{Ni}-49 \mathrm{Ti}$ and Ni-30Pt-50Ti (at.\%) shape memory alloys were oxidized isothermally in air over the temperature range of 500 to $900{ }^{\circ} \mathrm{C}$. The microstructure, composition, and phase content of the scales were studied by SEM, EDS, XRD, and metallography. Extensive plan view SEM/EDS identified various features of intact or spalled scale surfaces. The outer surface of the scale was a relatively pure $\mathrm{TiO}_{2}$ rutile structure, typified by a distinct highly striated and faceted crystal morphology. Crystal size increased significantly with temperature. Spalled regions exhibited some porosity and less distinct features. More detailed information was obtained by correlation of SEM/EDS studies of $700{ }^{\circ} \mathrm{C} / 100 \mathrm{hr}$ cross-sections with XRD analyses of serial or taper-polishing of plan surfaces. Overall, multiple layers exhibited graded mixtures of $\mathrm{NiO}, \mathrm{TiO}_{2}, \mathrm{NiTiO}_{3}, \mathrm{Ni}(\mathrm{Ti})$ or $\mathrm{Pt}(\mathrm{Ni}, \mathrm{Ti})$ metal dispersoids, $\mathrm{Ni}_{3} \mathrm{Ti}_{\text {or }} \mathrm{Pt}_{3} \mathrm{Ti}$ depletion zones, and substrate, in that order. The NiTi alloy contained a 3 at.\% Fe impurity that appeared in embedded localized Fe-Ti-rich oxides, while the NiPtTi alloy contained a 2 v/o dispersion of TiC that appeared in lower layers. The oxidation kinetics of both alloys (in a previous report) indicated parabolic growth and an activation energy $(250 \mathrm{~kJ} / \mathrm{mole})$ near those reported in other Ti and NiTi studies. This is generally consistent with $\mathrm{TiO}_{2}$ existing as the primary scale constituent, as described here.
\end{abstract}

\section{Introduction}

Shape memory alloys (SMA) have been studied and developed for various medical and activating or switching devices that take advantage of a reversible martensitic transformation. While NiTi remains the most widely used composition, the phenomenon is characteristic of many B2 and other ordered intermetallic systems. One distinctive attribute of the NiTi-based nitinol system is the proximity of the transformation range to room temperature. More recently, however, systems with elevated temperature capability have been proposed. For example, ternary alloys based on the Ni-Pt-Ti system have demonstrated transformation temperatures in the range of 300 to $500{ }^{\circ} \mathrm{C}$ (Ref. 1). This offers possible applications as turbine engine actuator devices in hot environments. Commonly used hot fabrication techniques (rolling, wire drawing) provide additional motivations to study oxidation behavior. Alternatively, SMA biomaterial implant devices often use pre-oxidized surfaces to facilitate tissue adhesion and bone growth to the $\mathrm{TiO}_{2}$ scale as well as limit the amount of toxic Ni that may dissolve in vivo fluids. Furthermore, Pt-modified alloys offer improved imaging in atomic number-sensitive CAT scans. Accordingly, the oxidation kinetics have been studied for a Ni-30Pt-50Ti SMA over the temperature range of 500 to $900{ }^{\circ} \mathrm{C}$ in a prior companion study (Ref. 2) and compared to those of a commercial Ni-49Ti alloy. Generally, it was found that the kinetics of the NiPtTi alloy were lower than those of the binary by about a factor of 4 , but with a similar temperature dependence or activation energy. The purpose of this paper is to augment these findings with corresponding microstructural and phase characterization of the scales using XRD and SEM/EDS, in both plan and transverse cross-section samples. 


\section{Prior Literature}

NiTi alloy oxidation has been the focus of a number of studies, all finding essentially parabolic kinetics. The kinetic results are summarized in Table 1 (Ref. 2) for an overall temperature range of 450 to $1000{ }^{\circ} \mathrm{C}$ and for durations as short as $4 \mathrm{hr}$ and as long as $100 \mathrm{hr}$. The results are grouped for those having high or low activation energies of 220 to $260 \mathrm{~kJ} / \mathrm{mole}$ and 130 to $150 \mathrm{~kJ} / \mathrm{mole}$, respectively. By comparison, the activation energy of pure $\mathrm{Ti}$ is close to $220 \mathrm{~kJ} / \mathrm{mole}$ and that of pure $\mathrm{Ni}$ varies over 110 to $170 \mathrm{~kJ} / \mathrm{mole}$, possibly an effect of uncontrolled impurities. While it is tempting to attribute the lower range of NiTi data to some effect of $\mathrm{NiO}$ scales, this appears not to be the case as discussed below. At present, the reason for two groupings of activation energy is unresolved.

TABLE 1.-COMPARATIVE ARRHENIUS PARAMETERS FOR Ni-X-Ti OXIDATION KINETICS

\begin{tabular}{|c|c|c|c|c|c|c|c|}
\hline & & $A \exp (-Q / F$ & & & & & \\
\hline alloy, at.\% & $\underset{\left(\mathrm{mg}^{2} / \mathrm{cm}^{4} \mathrm{hr}\right)}{\mathrm{A}}$ & $\begin{array}{c}A^{\prime} \\
\left(g^{2} / \mathrm{cm}^{4} s\right)\end{array}$ & $\begin{array}{c}\mathbf{Q}, \\
\text { (kJ/mole) }\end{array}$ & $\begin{array}{l}\text { Temperature } \\
\left({ }^{\circ} \mathrm{C}\right)\end{array}$ & $\begin{array}{c}\text { Duration } \\
\text { (hr) }\end{array}$ & $r^{2}$ & Reference \\
\hline Ni30Pt50Ti & $1.54 \times 10^{12}$ & $4.29 \times 10^{2}$ & 250 & $500-900$ & 100 & 0.98 & Smialek (2010) \\
\hline $\mathrm{Ni49Ti}$ & $6.39 \times 10^{12}$ & $1.78 \times 10^{3}$ & 249 & $600-900$ & 100 & 1.00 & Smialek (2010) \\
\hline $\mathrm{Ni50Ti}$ & $3.46 \times 10^{12}$ & $9.61 \times 10^{2}$ & 259 & $750-950$ & 60 & 0.99 & Satow (1974) \\
\hline $\mathrm{Ni50Ti}$ & $4.85 \times 10^{10}$ & 13.48 & 225 & $700-1000$ & 6 & 0.96 & Chu (1996) \\
\hline $\mathrm{Ni50Ti}$ & $1.92 \times 10^{6}$ & $5.33 \times 10^{-4}$ & 136 & $450-750$ & 4 & 1.00 & Xu (2004) \\
\hline $\mathrm{Ni50Ti}$ & $7.31 \times 10^{6}$ & $2.03 \times 10^{-3}$ & 152 & $530-650$ & 4 & 0.96 & Vojtêch (2008) \\
\hline Ni10Cu50Ti & $1.61 \times 10^{7}$ & $4.47 \times 10^{-3}$ & 143 & $700-925$ & 6 & 1.00 & $\operatorname{Lin}(2009)$ \\
\hline $\mathrm{Ti}(\mathrm{K})$ & $1.66 \times 10^{10}$ & 4.60 & 219 & $500-950$ & N.A. & N.A. & Kofstad (1988) \\
\hline $\mathrm{Ni}(\mathrm{K})$ & $7.02 \times 10^{3}$ & $1.95 \times 10^{-6}$ & 112 & $600-1200$ & N.A. & N.A. & Kofstad (1988) \\
\hline $\mathrm{Ni}(\mathrm{G})$ & $1.63 \times 10^{6}$ & $4.52 \times 10^{-4}$ & 167 & $550-700$ & 6 & 0.99 & Gulbransen (1954) \\
\hline $\mathrm{Ni}(\mathrm{P})$ & $1.38 \times 10^{6}$ & $3.84 \times 10^{-4}$ & 174 & $815-1370$ & $1-2$ & 1.00 & Progar (1964) \\
\hline $\mathrm{Ni}(\mathrm{A})$ & $5.22 \times 10^{6}$ & $1.45 \times 10^{-3}$ & 154 & $500-800$ & 109 & 0.98 & Atkinson (1982) \\
\hline
\end{tabular}

In an aggregate picture of the scale make-up, multiple layers are seen to grow with $\mathrm{TiO}_{2}$ rutile as the outer and predominant scale layer. This gives way to a mixed layer of $\mathrm{TiO}_{2}$ and $\mathrm{NiTiO}_{3}$. Dispersed $\mathrm{Ni}(\mathrm{Ti}$ ) metal particles and porosity are often observed in the scale. Ti-depletion zones overlie the metal substrate structure, showing $\mathrm{Ni}_{\mathrm{x}} \mathrm{Ti}(\mathrm{x}=2,3,4)$ on top of a TiNi layer having a depressed $\mathrm{M}_{\mathrm{s}}$ temperature due to $\mathrm{Ti}$ denudation.

Specifically, Satow, Isano, and Honma, in perhaps the first reported oxidation study of NiTi shape memory alloys (1974) (Ref. 3), used a succession of 20 light polishing treatments for layer-by-layer XRD analysis of the scale. They found structures of outer $\mathrm{TiO}_{2}$, followed by a graded mixture with $\mathrm{NiTiO}_{3}$, a porous $\mathrm{Ni}(\mathrm{Ti})$ layer, $\mathrm{Ni}_{3} \mathrm{Ti}$, and finally unaffected $\mathrm{TiNi}$. Chan et al. found primarily $\mathrm{TiO}_{2} \mathrm{scales}$, with a depletion zone corresponding to " $\sim \mathrm{Ni}_{2} \mathrm{Ti}$ " (Ref. 4). Chu et al. (Ref. 5) found $\mathrm{TiO}_{2}$ external scales, with metallic $\mathrm{Ni}(\mathrm{Ti})$ particles dispersed in an intermediate scale layer, followed by a $\mathrm{Ni}_{3} \mathrm{Ti}$ depletion zone. Firstov et al. (Ref. 6) oxidized NiTi for $30 \mathrm{hr}$ at various temperatures. After $30 \mathrm{~min}$, XRD analysis revealed $\mathrm{TiO}$ at 300 to $500{ }^{\circ} \mathrm{C}, \mathrm{TiO}_{2}$ at $600{ }^{\circ} \mathrm{C}$, adding some $\mathrm{NiO}$ at $700{ }^{\circ} \mathrm{C}$ and $\mathrm{NiTiO}_{3}$ at $800{ }^{\circ} \mathrm{C}$. The B19' martensitic room-temperature phase gave way to the $\mathrm{B} 2$ parent phase due to selective Ti oxidation. 
With increasing oxidation temperature, $\mathrm{Ni}_{3} \mathrm{Ti}$ depletion zones increased while a trace of elemental $\mathrm{Ni}$, very near the gas surface, decreased. Nitinol wires were oxidized for $6 \mathrm{hr}$ at 400 to $1000{ }^{\circ} \mathrm{C}$ and characterized (Ref. 7) as external $\mathrm{TiO}_{2}$ scales, followed by bands of $\mathrm{Ni}$ intermixed with $\mathrm{TiO}_{2}$, and underlying $\mathrm{Ni}_{3} \mathrm{Ti}, \mathrm{Ni}_{4} \mathrm{Ti}$ depletion layers. Similarly, Vojtěch et al. oxidized nitinol wire for $4 \mathrm{hr}$ at 430 to $650{ }^{\circ} \mathrm{C}$ (Ref. 8), resulting in $\mathrm{TiO}_{2}$ scales, while Xu et al. (Ref. 9) oxidized NiTi for $4 \mathrm{hr}$ at 450 to $750{ }^{\circ} \mathrm{C}$ and found primarily $\mathrm{TiO}_{2}$ scale growth, with Ti-denuded internal oxidation and $\mathrm{Ni}_{3} \mathrm{Ti}$ depletion zone layers. Partial spallation occurred after $750{ }^{\circ} \mathrm{C}$ oxidation, revealing somewhat of an open or porous interface and individual oxide crystallites. Tian et al. (Refs. 10 and 11) oxidized a high-temperature Ni-30Pd-50Ti at.\% shape memory alloy at $900{ }^{\circ} \mathrm{C}$ for $46 \mathrm{hr}$ and identified a lenticular, oriented $\mathrm{TiO}_{2}$-rich outer scale, with an inner porous layer containing $\mathrm{NiTiO}_{3}$ and $\mathrm{Ti}_{4} \mathrm{Pd}_{2} \mathrm{O}$. Below the scale, a $250 \mu \mathrm{m} \mathrm{Ti}$ depletion zone in the substrate was found to cause a dramatic rise in hardness. These alloys oxidized somewhat slower than binary NiTi and pure Ti. Most recently Lin and Wu oxidized another ternary alloy, $\mathrm{Ni10Cu} 50 \mathrm{Ti}$, at 700 to $1000^{\circ} \mathrm{C}$ for $6 \mathrm{hr}$ (Ref. 12). They found highly-layered structures of external $\mathrm{Cu}_{2} \mathrm{O}$, $\mathrm{TiO}_{2}+\mathrm{TiNiO}_{3}, \mathrm{TiO}_{2}+\mathrm{Ni}(\mathrm{ss})$ and $(\mathrm{Ni}, \mathrm{Cu})_{3} \mathrm{Ti}$ depletion layers.

The following, then, is an attempt to characterize the various scale phases and layers that form on the subject Ni-49Ti and Ni-30Pt-50Ti shape memory alloys that were reported in an earlier study of the 500 to $900{ }^{\circ} \mathrm{C}$ oxidation kinetics (Refs. 2 and 13). While XRD was used to identify phases, a wide variety of scale microstructural features were detailed by SEM/EDS. Most samples were studied in plan of the oxidized surface, but $700{ }^{\circ} \mathrm{C}$ samples were characterized in more detail by cross-section microstructure and serial-section XRD.

\section{Materials and Experimental Procedure}

A conventional Nitinol shape memory alloy was obtained commercially from Johnson Matthey Inc., in the form of $0.125 \mathrm{in}$. $(3.18 \mathrm{~mm})$ rolled plate which was then surface ground to $0.100 \mathrm{in}$. $(2.54 \mathrm{~mm})$ and electro-discharge machining (EDM) sectioned into $3 / 4$ by $3 / 4$ in. $(1.9$ by $1.9 \mathrm{~cm})$ coupons. Chemical analysis of the Ni-49Ti alloy (subsequently called Ni49Ti), performed by ICP, yielded Ni-49.3Ti-3.2Fe at.\%. The Ni-30Pt-50Ti alloy (subsequently called Ni-30Pt-50Ti) was produced in our laboratory by vacuum induction melting in a graphite crucible, cast into a 1 in. diameter by 4 in. $(2.54 \mathrm{~cm}$ diameter by $10.2 \mathrm{~cm}$ ) long cylinder, and forged to $0.42 \mathrm{in} .(1.07 \mathrm{~cm})$, under a $1093{ }^{\circ} \mathrm{C}$ preheat. The plate was EDM sectioned into 0.100 in. $(2.54 \mathrm{~mm})$ thick by 0.6 by 0.6 in. $(1.5$ by $1.5 \mathrm{~cm})$ coupons. The primary alloy phase at room temperature was the B19 ordered orthorhombic martensite, with an unintentional $2.1 \mathrm{vol} \%$ TiC dispersed particulate phase in the Ni-30Pt-50Ti material and an overall chemistry of $20.10 \mathrm{Ni}$, 49.66 Ti, 29.1 Pt, 0.85 C, 0.2 O, 0.06 N, and 0.02 Fe atomic percent. Oxidation coupons were polished to a 600 grit finish with SiC emery paper and ultrasonically cleaned in detergent, then ethyl alcohol.

The samples were oxidized in dried, bottled air, flowing at $100 \mathrm{~cm}^{3} / \mathrm{min}$., at 500,600, 700, and $800{ }^{\circ} \mathrm{C}$ for $100 \mathrm{hr}$, and at $900{ }^{\circ} \mathrm{C}$ for $10 \mathrm{hr}$ in a Cahn 1000 thermogravimetric analysis (TGA) electrobalance using an alumina tube and resistance furnace. The detailed treatment of the TGA kinetic data was discussed in the companion paper (Ref. 2).

The surface of oxidized coupons were characterized by x-ray diffraction (XRD). Select $700{ }^{\circ} \mathrm{C}$ samples were also examined by serial-sectioning the binary Ni49Ti alloy or by microfocus XRD by low angle $\left(\leq 1^{\circ}\right)$ taper-section polishing of the ternary Ni-30Pt-50Ti alloy. Here the oxidized surface was carefully polished with 600 grit emery paper, finishing with 4000 . Periodically the sample weight was recorded and the sample was submitted for XRD analyses. The relative amounts of phases were estimated from the diffracted intensities of each phase using a commercial software program.

FEG-SEM/EDS scanning electron microscopy was performed on oxidized surfaces using a conductive carbon coating and a typical accelerating voltage of $15 \mathrm{kV}$. Scale feature chemistry was characterized by EDS using a windowless detector. The primary (and secondary satellite) peaks observed in this study follow in order of energy level as $\mathrm{CK}_{\alpha}$, $\left(\mathrm{Ti} \mathrm{L}_{1}\right.$, Ti $\left.\mathrm{L}_{\alpha}\right) \mathrm{OK}_{\alpha}$, Ni L $\mathrm{L}_{1}$, Ni $\mathrm{L}_{\alpha}$, $\left(\mathrm{Pt} \mathrm{M}_{2}\right) \mathrm{Pt} \mathrm{M}_{\alpha}$, $\left(\mathrm{Pt} \mathrm{M}_{\gamma}\right)$, Ti K $\mathrm{K}_{\alpha},\left(\mathrm{Ti} \mathrm{K}_{\beta}\right), \mathrm{Fe}$ $\mathrm{K}_{\alpha},\left(\mathrm{Fe} \mathrm{K}_{\beta}\right)$, Ni $\mathrm{K}_{\alpha},\left(\mathrm{Ni} \mathrm{K}_{\beta}\right)$, and $\left(\mathrm{Pt} \mathrm{L}_{1}, \mathrm{Pt} \mathrm{L}_{\alpha}\right)$ over the energy range of about 0.2 to $10.0 \mathrm{kev}$. 


\section{Results}

The as-received microstructure of the Ni-30Pt-50Ti alloy is shown in Figure 1, as a dispersion of TiC in a matrix of heavily twinned martensite. A cross-section of the $500{ }^{\circ} \mathrm{C}$ oxidized sample reveals a thin, $\sim 0.2 \mu \mathrm{m}$, Ti-O rich surface scale. The corresponding EDS results, Figure 2, support this chemistry, allowing for beam overlap at features smaller than the electron interaction volume, at $\sim 1 \mathrm{~m}^{3}$. (Here and afterwards, the abscissa refers to relative intensity in arbitrary units while the ordinate is the standard electron energy in $\mathrm{keV}$ ).
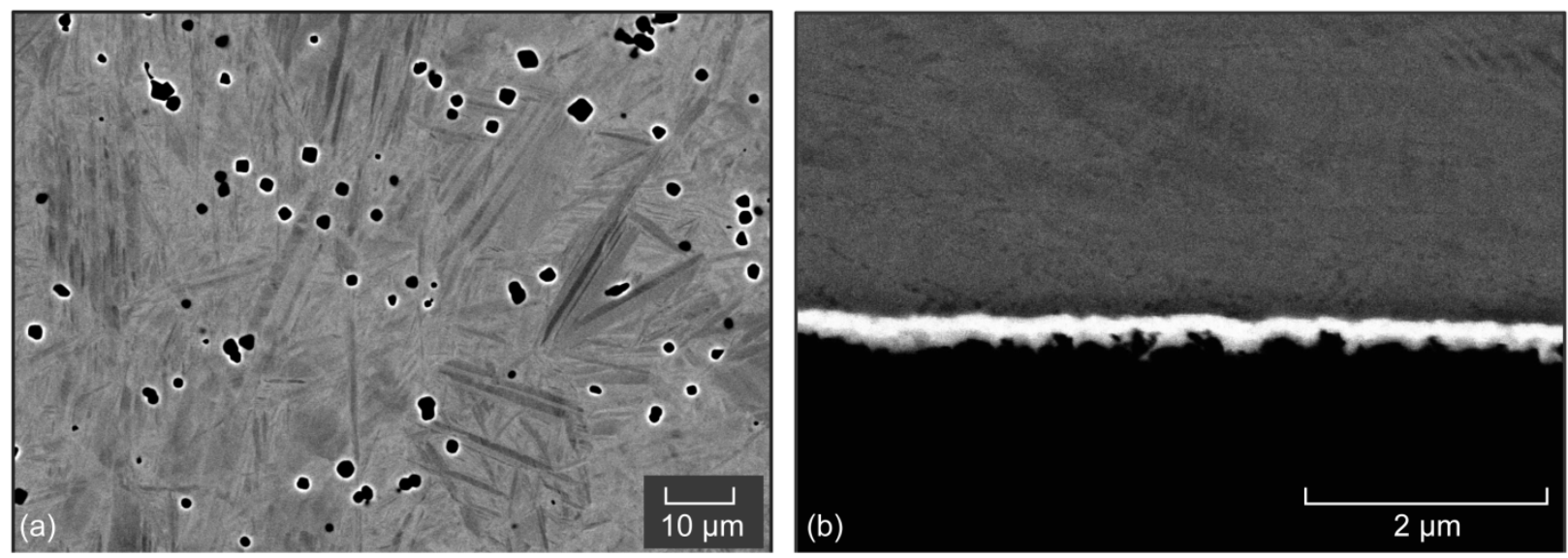

Figure 1.-Cross-section microstructure of Ni30Pt50Ti (a) as-received and (b) $500{ }^{\circ} \mathrm{C}, 100 \mathrm{hr}$ oxidation.

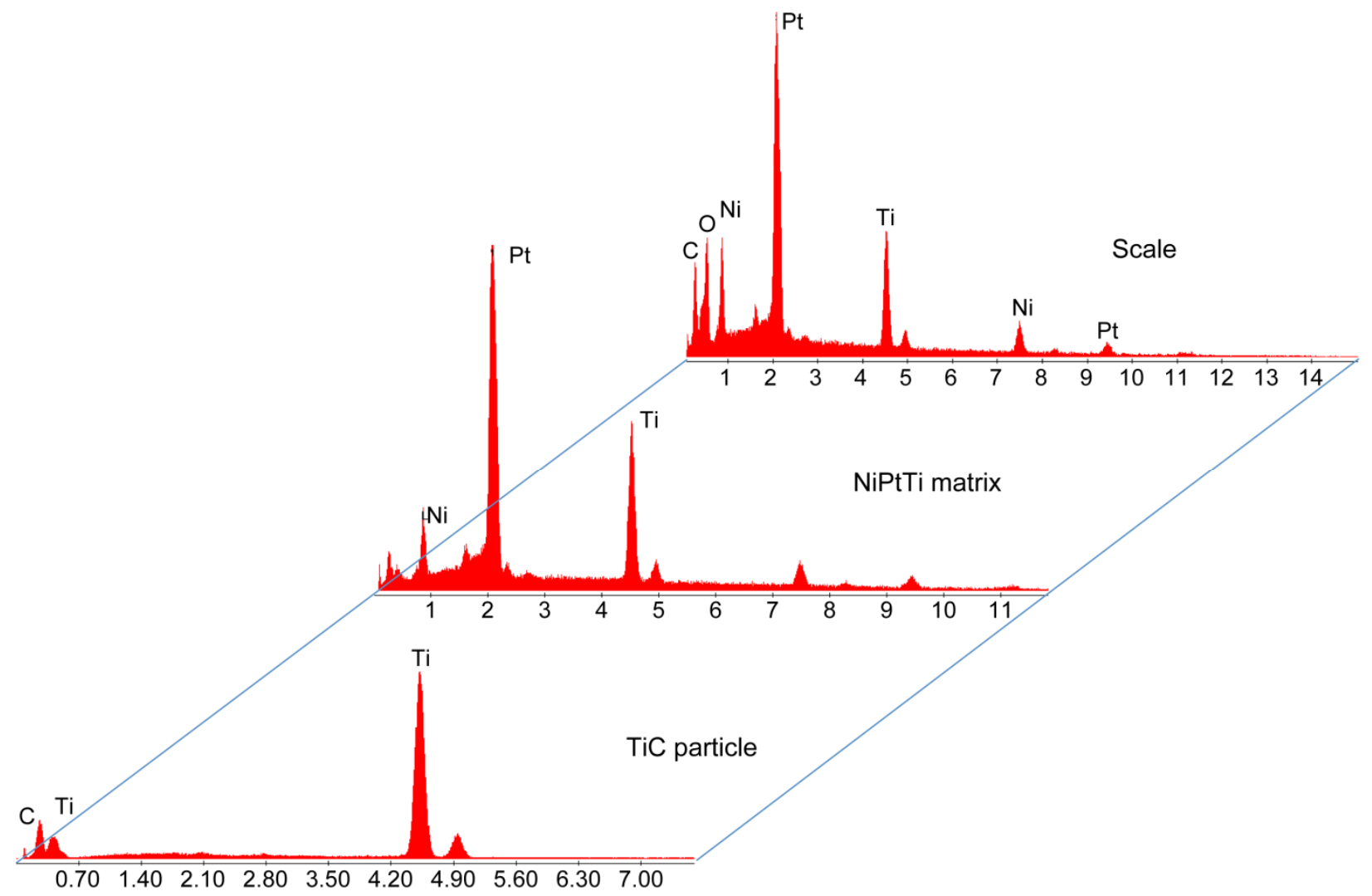

Figure 2.-SEM/EDS identification of dark TiC particles, Ni30Pt50Ti matrix, and thin scale in Figure 1. 
Spalling after cool-down was observed for some samples, shown by surface macrographs and weight change (Ref. 2). The relative amount of oxide weight loss on cool-down was compared to the final oxygen weight gain before cool-down. The relative amount of spalling was estimated, up to $\sim 70$ percent for Ni49Ti above $700{ }^{\circ} \mathrm{C}$ and up to $\sim 55$ percent for Ni-30Pt-50Ti above $800{ }^{\circ} \mathrm{C}$, correcting for stoichiometry and assuming primarily $\mathrm{TiO}_{2}$ scales. Thus, it is recognized that surface characterizations discussed below will sometimes correspond to inner scale layers exposed due to spalling.

\section{Overview of XRD Phase Analysis}

A summary of the primary scale and metal phases identified by XRD of the oxidized surfaces is shown in Table 2. Representative patterns demonstrating these results are presented in Figures 3 and 4 for Ni49Ti and Ni-30Pt-50Ti after various exposures. The as-received room temperature metal phases were the cubic B2 NiTi "austenite" and the orthorhombic B19 Pt(Ni)Ti martensite structures. For both alloys, $\mathrm{TiO}_{2}$ rutile was the predominant surface scale. The anatase phase may have been present, but only in very small amounts at low temperatures $\left(500\right.$ and $\left.600{ }^{\circ} \mathrm{C}\right)$. The $\mathrm{NiTiO}_{3}$ nickel titanate phase appeared on both alloys and was more prevalent for the Ni-30Pt-50Ti alloy. $\mathrm{NiO}$ was not a major scale phase, but appeared with preferred orientation on the Ni-30Pt-50Ti alloy.

TABLE 2.-XRD PHASE SUMMARY FOR OXIDIZED Ni(Pt)Ni SHAPE MEMORY ALLOYS

a) Ni49Ti; b) Ni-30Pt-50Ti

\begin{tabular}{|c|c|c|c|c|c|c|c|c|c|c|}
\hline \multicolumn{2}{|c|}{ a) $\mathrm{Ni} 49 \mathrm{Ti}$} & & \multirow[b]{2}{*}{ B2 } & \multirow[b]{2}{*}{$\mathrm{DO}_{24}$} & \multirow{2}{*}{\multicolumn{2}{|c|}{ A1 }} & \multirow[b]{2}{*}{ rutile } & \multirow[b]{2}{*}{ anatase } & & \multirow[b]{3}{*}{$\mathrm{NiO}$} \\
\hline & & & & & & & & & & \\
\hline $\mathrm{T}\left({ }^{\circ} \mathrm{C}\right)$ & $t(h)$ & scale & $\mathrm{NiTi}$ & $\mathrm{Ni}_{3} \mathrm{Ti}$ & $\mathrm{Ni}$ & & $\mathrm{TiO}_{2}$ & $\mathrm{TiO}_{2}$ & $\mathrm{NiTiO}_{3}$ & \\
\hline & & as-received & S & & & & & & & \\
\hline 500 & 100 & surface & $S$ & $W$ & & & $\mathrm{~W}$ & V.W. & $\mathrm{M}$ & \\
\hline 600 & 100 & surface & $M$ & $M$ & & & S & W & W & \\
\hline 700 & 100 & surface & & & & & S & & V.W. & \\
\hline 700 & 100 & spall & & & & & $S$ & & W & \\
\hline 800 & 100 & surface & & & & & S & & V.W. & \\
\hline 800 & 100 & spall & & & & & $S$ & & & \\
\hline 900 & 10 & surface & & & S & & S & & W & V.W. \\
\hline \multicolumn{11}{|c|}{ b) Ni30Pt50Ti } \\
\hline & & & B19 & $\mathrm{L1}_{2}$ & $\mathbf{L 1}_{0}$ & A1 & rutile & anatase & & \\
\hline \multirow[t]{2}{*}{$\mathrm{T}\left({ }^{\circ} \mathrm{C}\right)$} & $t(h)$ & scale & $\mathrm{Pt}(\mathrm{Ni}) \mathrm{Ti}$ & $\mathrm{Pt}_{3} \mathrm{Ti}$ & $\mathrm{NiPt}$ & $\mathrm{Pt}(\mathrm{Ni})$ & $\mathrm{TiO}_{2}$ & $\mathrm{TiO}_{2}$ & $\mathrm{NiTiO}_{3}$ & $\mathrm{NiO}$ \\
\hline & & as-received & $\mathrm{S}$ & & & & & & & \\
\hline 500 & 100 & surface & $S$ & M & M & & M & V.W. & & \\
\hline 600 & 100 & surface & W & $S$ & V.W. & S & M & W? & & \\
\hline 700 & 100 & surface & & W? & & $S$ & S & & $S$ & $M$ \\
\hline 800 & 100 & surface & & W? & & M & S & & W & \\
\hline 900 & 10 & surface & & & & $M$ & $\mathrm{~S}$ & & V.W. & \\
\hline
\end{tabular}




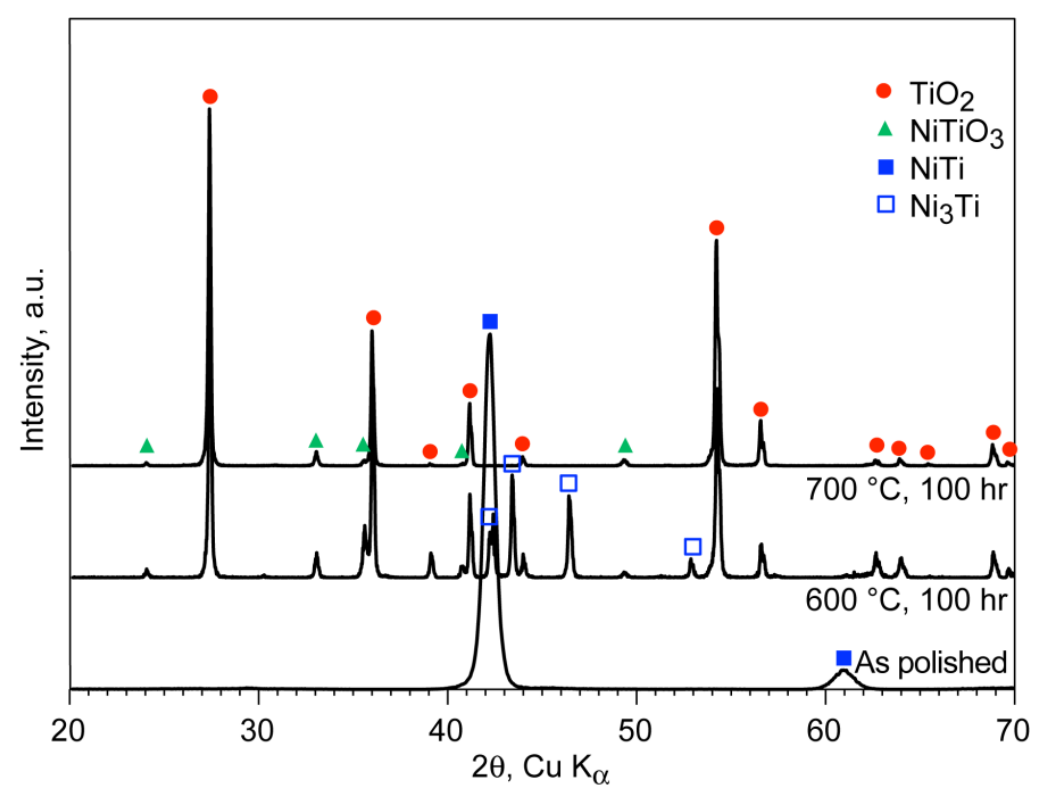

Figure 3.--Representative diffractometer scans of oxidized NiTi surface before and after $100 \mathrm{hr}$ oxidation at 600 and $700{ }^{\circ} \mathrm{C}$ showing patterns for $\mathrm{B} 2 \mathrm{NiTi}$ substrate, $\mathrm{Ni}_{3} \mathrm{Ti}$ depletion zone, and $\mathrm{TiO}_{2}$ and $\mathrm{NiTiO}_{3}$ scale phases.

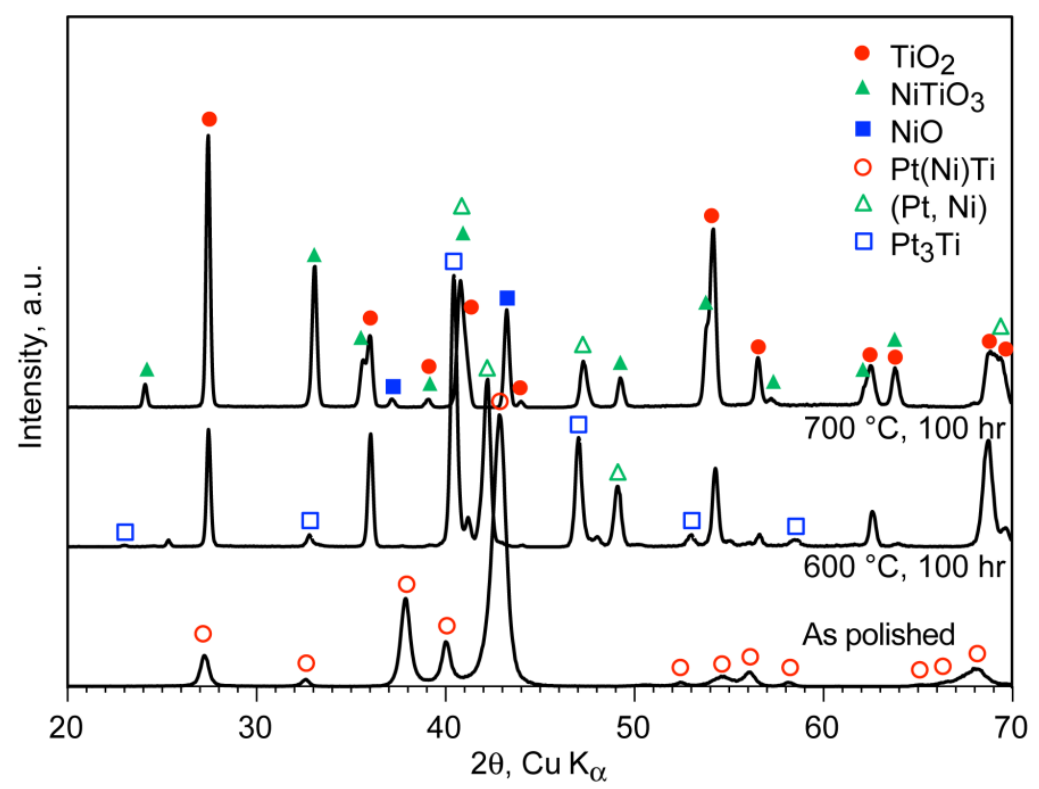

Figure 4.--Representative diffractometer scans of oxidized $\mathrm{Ni}(\mathrm{Pt}) \mathrm{Ti}$ surface before and after $100 \mathrm{hr}$ oxidation at 600 and $700{ }^{\circ} \mathrm{C}$ showing patterns for $\mathrm{B} 19 \mathrm{Pt}(\mathrm{Ni}) \mathrm{Ti}$ substrate, $\mathrm{Pt}(\mathrm{Ni})+\mathrm{Pt}_{3} \mathrm{Ti}$ depletion zone, and $\mathrm{TiO}_{2}$ and $\mathrm{NiTiO}_{3}$ scale phases. 
As already mentioned, cooling from oxidation at the higher temperatures produced massive spalling. Thus the true outer layer could not always be represented by a surface diffractometer scan. For Ni49Ti it was possible to collect some spalled material from the 700 and $800{ }^{\circ} \mathrm{C}$ scales for analyses; these confirmed essentially the same scale phases as the surface scans (Table 2). The metal phases identified after oxidation were $\mathrm{B} 2 \mathrm{NiTi}, \mathrm{L}_{2} \mathrm{Ni}_{3} \mathrm{Ti}$, and $\mathrm{A} 1 \mathrm{FCC}$ Ni for the Ni49Ti alloy and $\mathrm{B} 19 \mathrm{Pt}(\mathrm{Ni}) \mathrm{Ti}, \mathrm{Pt}_{3} \mathrm{Ti}$, $\mathrm{L}_{0} \mathrm{NiPt}, \mathrm{FCC} \mathrm{Pt}(\mathrm{Ni})$ and a $\mathrm{D} 0_{19}$ phase for the Ni-30Pt-50Ti alloy.

\section{Serial Polishing of Ni49Ti, Taper Section of Ni-30Pt-50Ti, and SEM Cross-Sections After $700{ }^{\circ} \mathrm{C}$ Oxidation}

\section{Ni49Ti XRD Results}

The cross-sectional microstructure of a duplicate Ni49Ti sample oxidized at $700{ }^{\circ} \mathrm{C}$ for $100 \mathrm{hr}$ is shown in Figure 5. The total scale and metal depletion zones are on the order of 30 and $17 \mu \mathrm{m}$, respectively. Multiple layers are clearly delineated. Some representative diffractometer scans highlighting the major phases are shown for the $700{ }^{\circ} \mathrm{C}$ samples in Figure 6. With no polishing ( $\mathrm{P} 0$ ), $\mathrm{TiO}_{2}$, and $\mathrm{NiTiO}_{3}$ are seen as the major surface phases. After slight polishing (P2), the relative amount of $\mathrm{NiTiO}_{3}$ increases. Finally, near the substrate layer $(\mathrm{P} 7)$, metallic $\mathrm{Ni}$ and $\mathrm{Ni}_{3} \mathrm{Ti}$ are revealed. More detailed data showing the gradation of phase mass content (estimated) with surface polishing is listed in Table 3 and Figure 7 for the $700{ }^{\circ} \mathrm{C}$ samples. It should be noted in these analyses that the immediate underlying layers will contribute somewhat to the diffracted intensity because of significant penetration depths (many microns) in conventional XRD analyses. $\mathrm{TiO}_{2}$ rutile was the major oxide phase throughout the scale layers. Also, a small amount of $\mathrm{NiTiO}_{3}$ was mixed with $\mathrm{TiO}_{2}$ in the outer layers, reaching a maximum after about

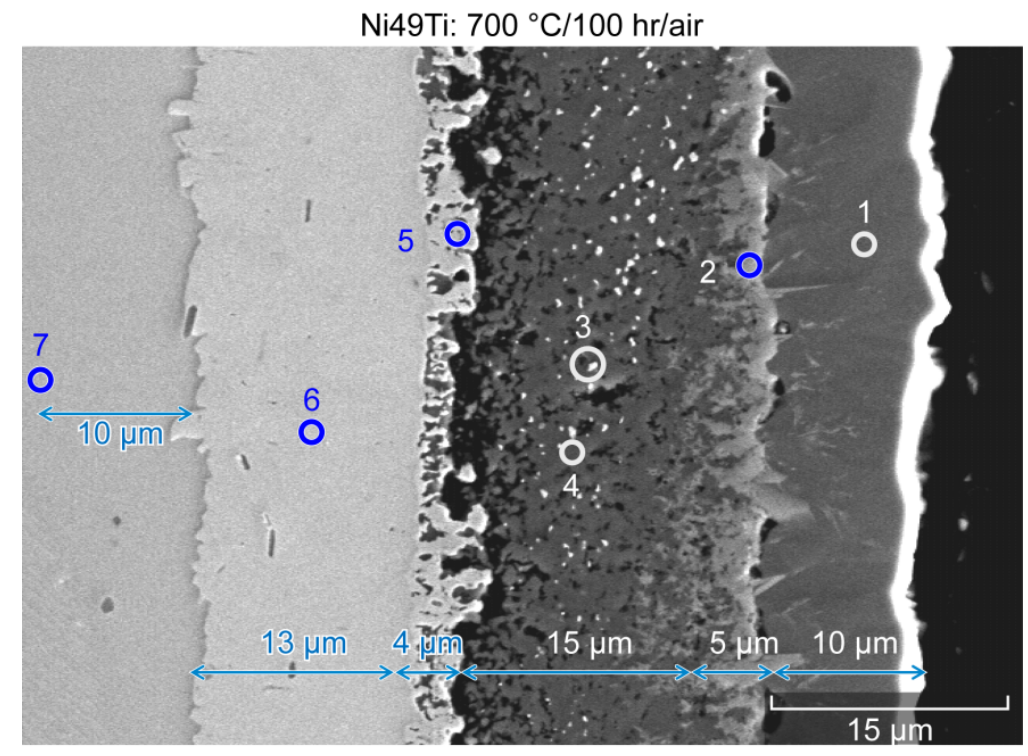

Figure 5.-Cross-section microstructure of multilayer scale on Ni49Ti after $100 \mathrm{hr} 700^{\circ} \mathrm{C}$ oxidation showing dispersed metal particles and thick depletion zone. 


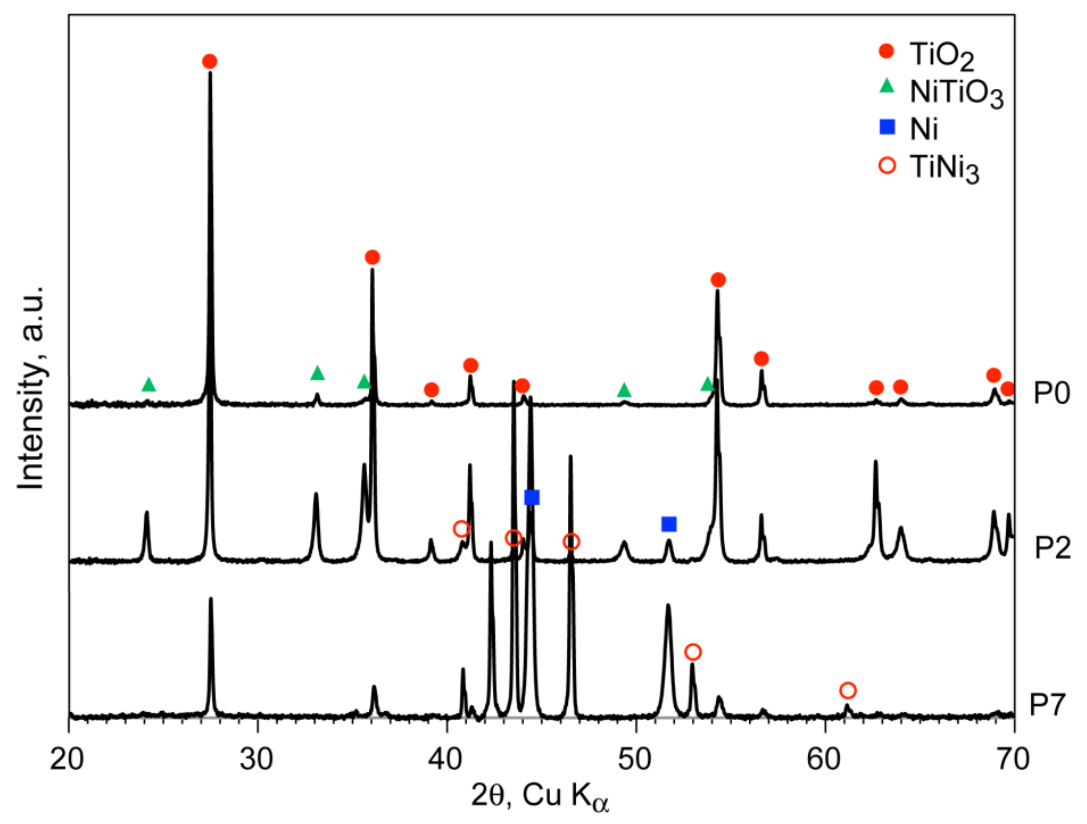

Figure 6.- Representative diffractometer scans of oxidized NiTi surface after $100 \mathrm{hr}$ oxidation at $700{ }^{\circ} \mathrm{C}$. Patterns for sequential serial-polishing layers show external $\mathrm{TiO}_{2}$ and $\mathrm{NiTiO}_{3}$ scale phases, then $\mathrm{Ni}$ and $\mathrm{Ni}_{3} \mathrm{Ti}$ depletion zone metal phases. (From Table 3, P0 refers to no polishing, P2 slight polishing, and P7 final polishing near the substrate).

TABLE 3.-SEMI-QUANTITATIVE ESTIMATE OF PHASES IN POLISHED SERIAL SECTIONS Ni49Ti, OXIDIZED AT $700{ }^{\circ} \mathrm{C}, 100 \mathrm{HR}$

\begin{tabular}{|c|c|c|c|c|c|c|c|}
\hline & $\begin{array}{c}\Delta W / A \\
\mathbf{m g} / \mathbf{c m}^{2}\end{array}$ & $\mathrm{TiO}_{2}$ & $\mathrm{NiTiO}_{3}$ & $\mathbf{N i}$ & $\mathrm{Ni}_{3} \mathrm{Ti}$ & $\mathrm{NiTi}$ & $\mathrm{Fe}_{3} \mathrm{O}_{4}$ \\
\hline $\mathrm{PO}$ & 0.00 & 95 & 5 & & & \multirow{4}{*}{$\mathrm{T}$} & \\
\hline $\mathrm{P} 1$ & 0.23 & 89 & 9 & 2 & $\mathrm{~T}$ & & $\mathrm{~T}$ \\
\hline $\mathrm{P} 2$ & 2.22 & 66 & 19 & 4 & 1 & & 4 \\
\hline P3 & 2.98 & 78 & 13 & 7 & 2 & & \\
\hline $\mathrm{P} 4$ & 3.79 & 80 & 7 & 10 & 3 & \multirow{5}{*}{1} & \\
\hline $\mathrm{P} 5$ & 6.13 & 78 & & 14 & 8 & & \\
\hline P6 & 8.20 & 54 & & 22 & 23 & & \\
\hline $\mathrm{P} 7$ & 9.35 & 13 & & 31 & 56 & & \\
\hline P7, edge & 9.35 & 4 & & 14 & 82 & & \\
\hline $\mathrm{TiO}_{2}$ scale & 10.67 & & & & & & \\
\hline
\end{tabular}

$\mathrm{T}=$ trace 


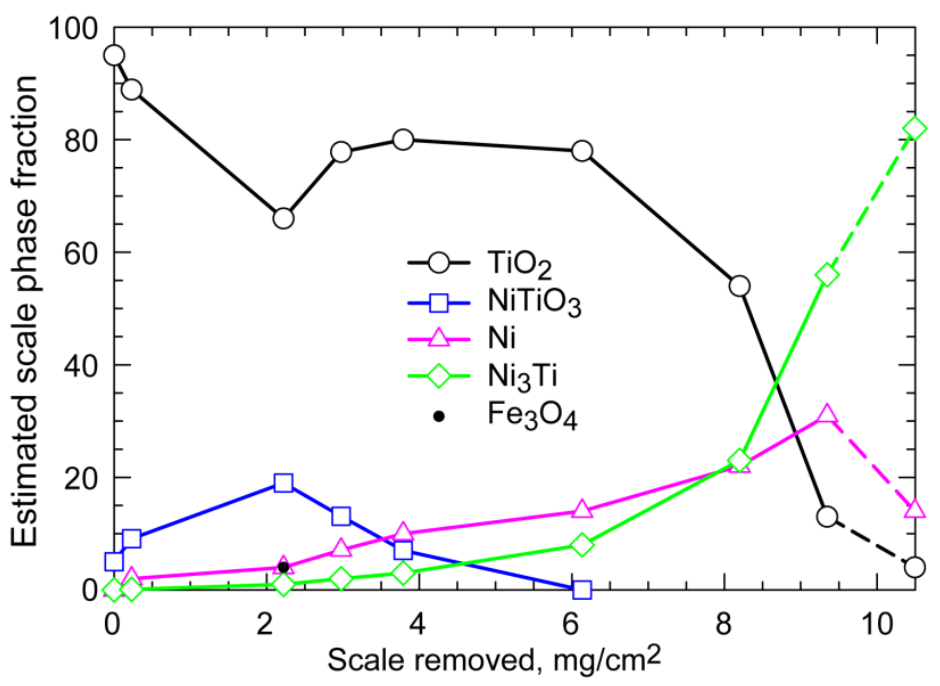

Figure 7.-Semi-quantitative trends in scale and depletion zone phase content: serial section XRD scans of Ni49Ti after $100 \mathrm{hr}$ $700{ }^{\circ} \mathrm{C}$ oxidation. $\mathrm{TiO}_{2}$ major scale phase, with lesser $\mathrm{NiTiO}_{3}$; metallic $\mathrm{Ni}$ and $\mathrm{Ni}_{3} \mathrm{Ti}$ increasing at inner scale layer.

$2 \mathrm{mg} / \mathrm{cm}^{2}$ scale removal, disappearing at $6 \mathrm{mg} / \mathrm{cm}^{2}$ removal. A small amount of Fe-rich oxide is identified, primarily at this maximum, arising from the Fe impurity in this alloy. Interestingly, a considerable amount of metallic Ni is seen to be increasing with depth throughout the scale. This Ni phase and the $\mathrm{TiO}_{2}$ scale finally diminish as the metallic $\mathrm{Ni}_{3} \mathrm{Ti}$ depletion zone is encountered. Most of the scale was removed during this sequence, as implied by the $9 \mathrm{mg} / \mathrm{cm}^{2}$ mass removal approaching the estimated amount of $11 \mathrm{mg} / \mathrm{cm}^{2}$ scale present. However, in this series, the underlying NiTi base alloy was never exposed. (Note: The final sequence of layer removal by polishing (dashed lines for P7) was graphed at an increased depth for clarity, corresponding to a tapered-edge scan).

\section{Cross-Sectional SEM/EDS of Ni49Ti}

For reference, the various features highlighted below are matched with corresponding XRD phase analyses of the serial sections in Table 4 . The $15 \mathrm{kV}$ EDS spectra corresponding to the outer layer in Figure 5 (point \#1 and spectra \#1) is a relatively featureless and pure $\mathrm{TiO}_{2}$, Figure 8. (Note the common overlap between the $\mathrm{O} \mathrm{K}_{\alpha}$ and $\mathrm{Ti} \mathrm{L}_{1}$, Ti $\mathrm{L}_{\alpha}$ lines. It is observed that these lines are not necessarily increased when there is a strong $\mathrm{Ti} \mathrm{K}_{\alpha}$ line. Therefore it assumed that these lines primarily reflect the contribution of $\mathrm{O} \mathrm{K}_{\alpha}$ ). Carbon is commonly present in EDS spectra because of the conductive carbon coating on all samples, but primarily at $15 \mathrm{kV}$ operating voltages. At $10 \mu \mathrm{m}$ down in Figure 5, some porosity and ingrown Fe-rich oxide platelets or needles are noted (point \#2 in Fig. 5), presumably associated with the 3 percent Fe impurity of this alloy. The corresponding EDS spectra (point \#2 in Fig. 8) reveals strong Fe and O peaks and moderate Ti and Ni. The $15 \mu \mathrm{m}$ layer below the needles (\#4 in Figs. 5 and 8 ) is again basically $\mathrm{TiO}_{2}$, but with a considerable dispersion of submicron Ni-rich particles (point \#3 in Figs. 5 and 8), probably metallic. (This oxide spectra in Fig. 8 is distinguished by the low $\mathrm{O}$ peak). As with many other instances to follow, there is contribution to small particle $(\leq 1 \mu \mathrm{m})$ EDS analyses from the surrounding areas. 
TABLE 4.-SERIAL AND TAPER SECTION XRD WITH CORRESPONDING SEM IMAGE AND EDS SPECTRA

a) $\mathrm{Ni49Ti}$

(SEM figure 5)

b) Ni30Pt50Ti

(SEM figures 10,16 )

XRD phase EDS figures: SEM point/EDS\# XRD phase EDS figures: SEM point/EDS\#

\begin{tabular}{|c|c|c|c|c|c|}
\hline $\mathrm{TiO}_{2}$ & 8 & 1,4 & $\mathrm{TiO}_{2}$ & 13,14 & 3,5 \\
\hline $\mathrm{NiTiO}_{3}$ & 8 & 2 & $\mathrm{NiO}$ & 13 & 1 \\
\hline $\mathrm{Fe}_{3} \mathrm{O}_{4}$ & 8 & 2 & $\mathrm{NiTiO}_{3}$ & 13 & 2 \\
\hline $\mathrm{Ni}$ & 8 & 3 & $\mathrm{Pt}(\mathrm{Ni})$ & 14 & 4,6 \\
\hline $\mathrm{Ni}_{3} \mathrm{Ti}$ & 9 & 5,6 & $(\mathrm{Pt}, \mathrm{Ni})_{3} \mathrm{Ti}$ & 15 & 7 \\
\hline \multirow[t]{4}{*}{ (NiTi) } & 9 & 7,8 & $\mathrm{Pt}_{3} \mathrm{Ti}$ & 15 & 8 \\
\hline & & & $\mathrm{Pt}(\mathrm{Ni}) \mathrm{Ti}$ & 17 & 11 (LGM) \\
\hline & & & $\mathrm{DO}_{19}$ & 17 & 10 (WGB) \\
\hline & & & $\mathrm{TiC}$ & 15,17 & $9,12(\mathrm{BP})$ \\
\hline
\end{tabular}

LGM = light grain matrix

WGB = white grain boundary

$\mathrm{BP}=$ black phase

Ni49Ti, $700^{\circ} \mathrm{C}$ cross section external scale

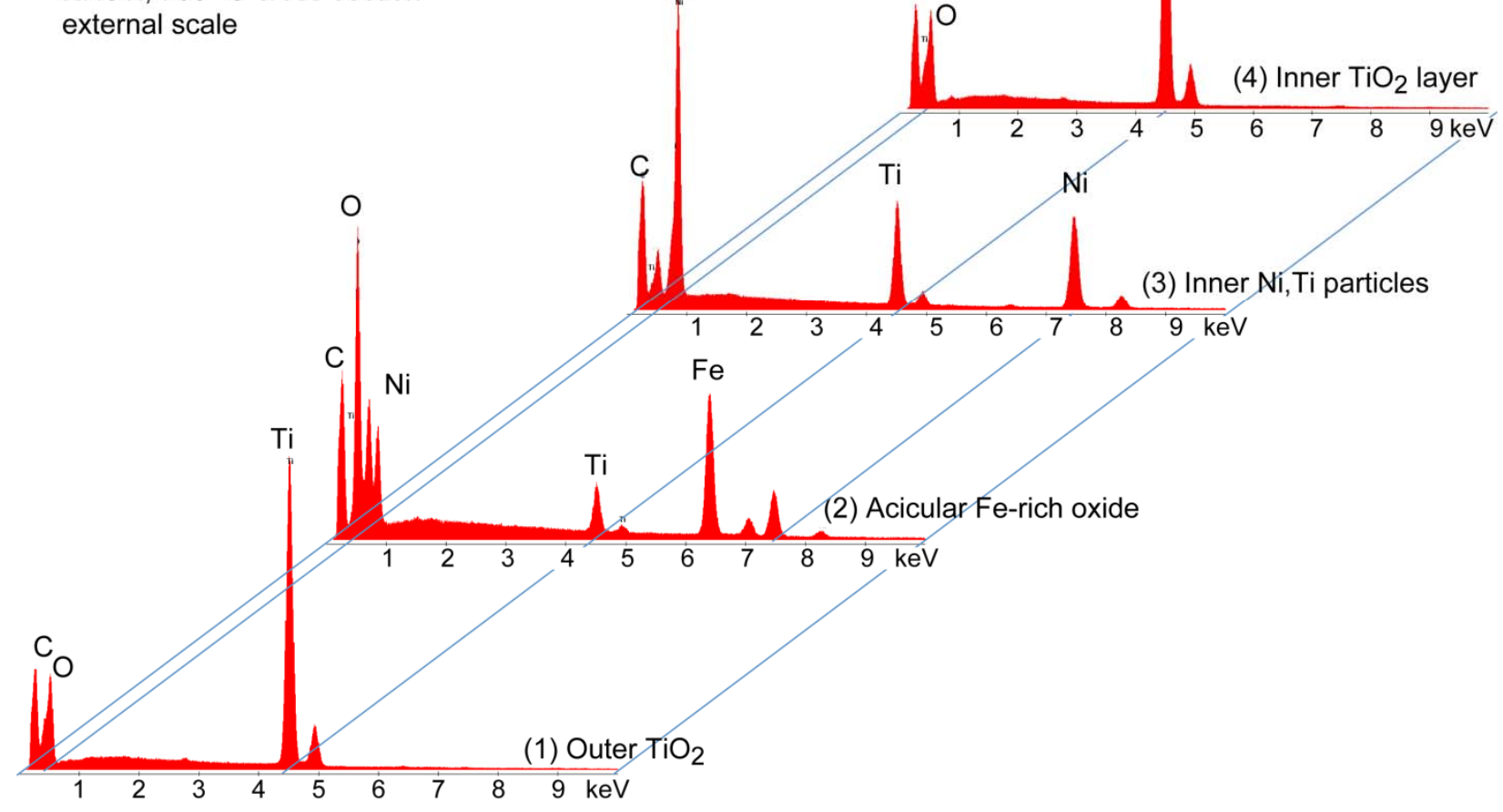

Figure 8.-SEM/EDS spectra corresponding to scale features 1 to 4 from Figure 5 (Ni49Ti after $100 \mathrm{hr} 700^{\circ} \mathrm{C}$ oxidation). 


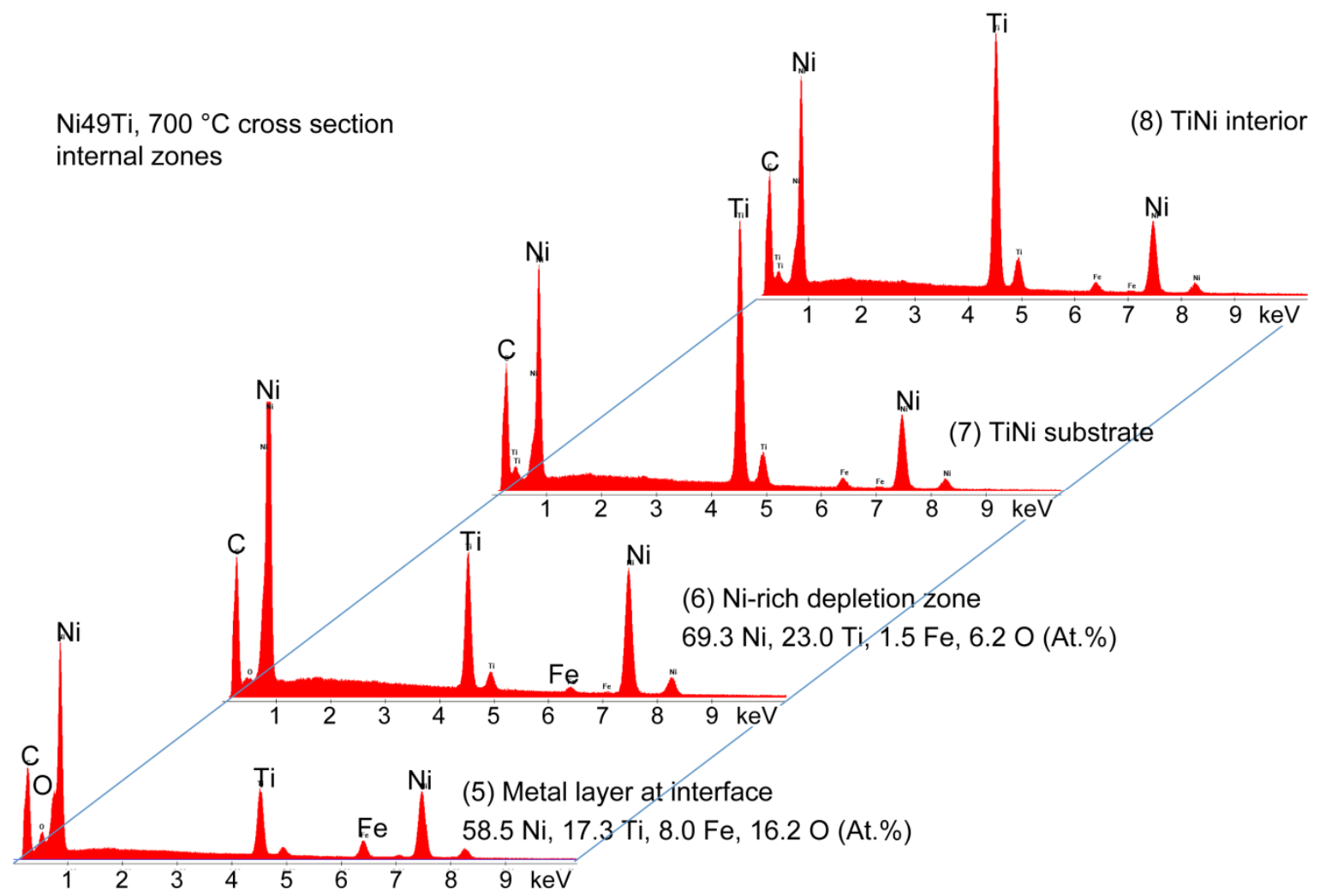

Figure 9.-SEM/EDS spectra corresponding to metallic subscale features 5 to 8 from Figure 5 (Ni49Ti after $100 \mathrm{hr} 700{ }^{\circ} \mathrm{C}$ oxidation).

Porosity is also increasing at inner regions of this layer, especially at the interface with the next lower layer. Here, the first connected metal phases appear, over a $4 \mu \mathrm{m}$ thickness, as finger-like protrusions (\#5 in Fig. 5), with porosity at the scale interface. The associated spectra in Figure 9 (\#5) is similar to that of the Ni(Ti) particles (point \#3 in Fig. 8), and the composition, corrected from EDS intensities, is near that of $\mathrm{Ni}_{3} \mathrm{Ti}$, with 8 percent $\mathrm{Fe}$ and a substantial amount of oxygen (16 percent). These are connected to the dense depletion zone (\#6 in Figs. 5 and 9), also presumably $\mathrm{Ni}_{3} \mathrm{Ti}$, but with less $\mathrm{Fe}$ (1.5 percent) and oxygen (6 percent) than the protrusions. Finally, at a level $\sim 10 \mu \mathrm{m}$ beneath this depletion zone, (\#7 in Figs. 5 and 9), the composition of the substrate appears to be essentially the same as the interior of the sample, (\#8 in Fig. 9).

The correspondences between serial polishing XRD phase analysis and specific cross-sectional $\mathrm{SEM} / \mathrm{EDS}$ features are listed in Table 4. In combination, they indicate primarily a duplex $\mathrm{TiO}_{2} \mathrm{scale}$ throughout, with indistinguishable $\mathrm{NiTiO}_{3}$ in the outer layer, interfacial $\mathrm{Fe}_{3} \mathrm{O}_{4}$ needles above the inner layer, metallic $\mathrm{Ni}$ particles dispersed within the inner layer, followed by $\mathrm{Ni}_{3} \mathrm{Ti}$ fingers and depletion zone before reaching the NiTi substrate.

\section{Ni-30Pt-50Ti XRD Results}

A cross section of the Ni-30Pt-50Ti sample oxidized at $700{ }^{\circ} \mathrm{C}$ for $100 \mathrm{hr}$ is shown in Figure 10. First, it appears that a $3-\mu \mathrm{m}$ outer layer is missing by polishing pullout. The remaining scale can be described as about $5 \mu \mathrm{m}$ of a three-phase zone and about $8 \mu \mathrm{m}$ of an inner layer dispersed with numerous metal particles. This yields a total scale of about $16 \mu \mathrm{m}$. It is about half the scale formed on Ni49Ti at the corresponding conditions, as expected for the overall $\mathrm{k}_{\mathrm{p}}$ ratio of Ni-30Pt-50Ti to Ni49Ti of 1/4. Diffractometer scans of the layers in plan view were primarily resolved by a taper section, as one early polishing step had removed the entire scale at one corner of the coupon, precluding a controlled serial- 


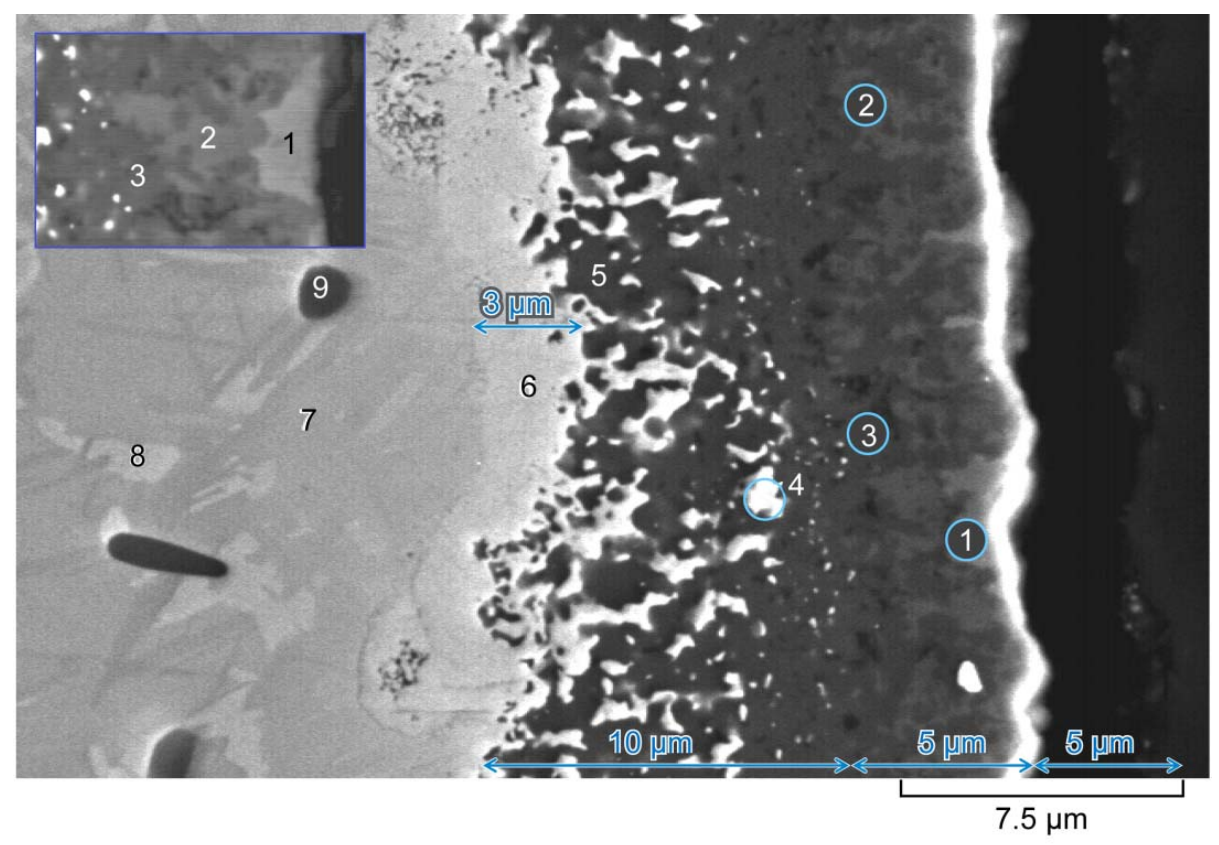

Figure 10.-Cross-section microstructure of multilayer scale on Ni30Pt50Ti after $100 \mathrm{hr}$ $700{ }^{\circ} \mathrm{C}$ oxidation showing mottled scale, dispersed metal, and diffuse depletion zone.

sectioning study. Instead the microfocus capability of a special diffractometer was used to locate the beam within a series of distinct adjacent bands, referred to later as "A" to "E", each a few mm wide, across the surface (not shown), and apply to different layers beneath the surface as revealed by taper polishing. Various polishing sequences $(0,1,2,3)$ are also identified by the numerical suffix, for example A0, A1, A2, A3, B2, B3, etc. for the original 5 bands, then F4 and F5 for polishing below the scale to the substrate as defined in Table 5. Some representative diffractometer scans highlighting the major phases are shown in Figure 11 for successive bands A0, D2, and F5, corresponding to increasing depth below the surface. Again, $\mathrm{TiO}_{2}$ was the primary outer scale phase, with noticeable $\mathrm{NiTiO}_{3}$ and $\mathrm{NiO}$ with preferred orientation. Deeper into the depletion zones, strong peaks for $\mathrm{Pt}_{3} \mathrm{Ti}$ were found with some $\mathrm{Pt}(\mathrm{Ni})$. Finally the unaffected substrate $(\mathrm{F})$, deep into the sample, showed primarily a $\mathrm{D} 0_{19}$ ordered orthorhombic phase (cf. $\mathrm{Ni}_{3} \mathrm{Sn}$ and $\mathrm{Ti}_{3} \mathrm{Al}$ structures) and $\mathrm{B} 19 \mathrm{Pt}(\mathrm{Ni}) \mathrm{Ti}$.

Semi-quantitative XRD mass \% results for scale phases of successive zones, through the $700{ }^{\circ} \mathrm{C}$ scale on the NiPtTi alloy, are also listed in Table 5. By inspection, it is apparent that the unpolished and 1st polishing scans, A0 and A1, are nearly identical and the values of the five "A" to "E" bands identified in the 2nd and 3rd polishing series are fairly similar. The values for similar bands were thus averaged and presented in Figure 12(a) for primary scale phases and Figure 12(b) for primary metallic phases, to provide a semiquantative overview of the trend in surface phases with depth. $\mathrm{TiO}_{2}$ rutile was the predominant outer scale phase, at least through band " $\mathrm{C}$ ", with a noticeable concentration of $\mathrm{NiTiO}_{3}$. The latter phase was localized in the outer layer and decreased in the inner bands. A small amount of $\mathrm{NiO}$ was detected in the outermost layers. When presenting the metallic phases, Figure 12(b), it is apparent that some metallic FCC Pt(Ni) increases from 10 percent in the outer layer to about 40 percent at band "C". In band " $\mathrm{D}$ ", $\mathrm{Pt}_{3} \mathrm{Ti}$ takes over as a primary phase, with $\mathrm{Pt}(\mathrm{Ni})$ and $\mathrm{Pt}(\mathrm{Ni}) \mathrm{Ti}$ phases. Band "C" can thus be seen as a transition zone to the underlying metallic depletion zones. The last band, believed to be unaffected substrate (E3, F4, and F5 in Table 5), consists of B19 Pt(Ni)Ti, hexagonal phase, and the TiC dispersion. The hexagonal phase $(\mathrm{c}=5.496 \AA, \mathrm{a}=4.500 \AA)$ appears to belong to space group P63/mmc (194) with the $\mathrm{Ni}_{3} \mathrm{Sn}$ prototype structure (D0 $0_{19}$ ). It is isostructural with an $\mathrm{Mn}_{12} \mathrm{Pt}_{4} \mathrm{~N}$ phase and has a good lattice parameter match, but little relation to this composition. To our knowledge, it has not been previously identified in the NiPtTi system. This phase will be referred to subsequently as "D0 $0_{19}$ ". 


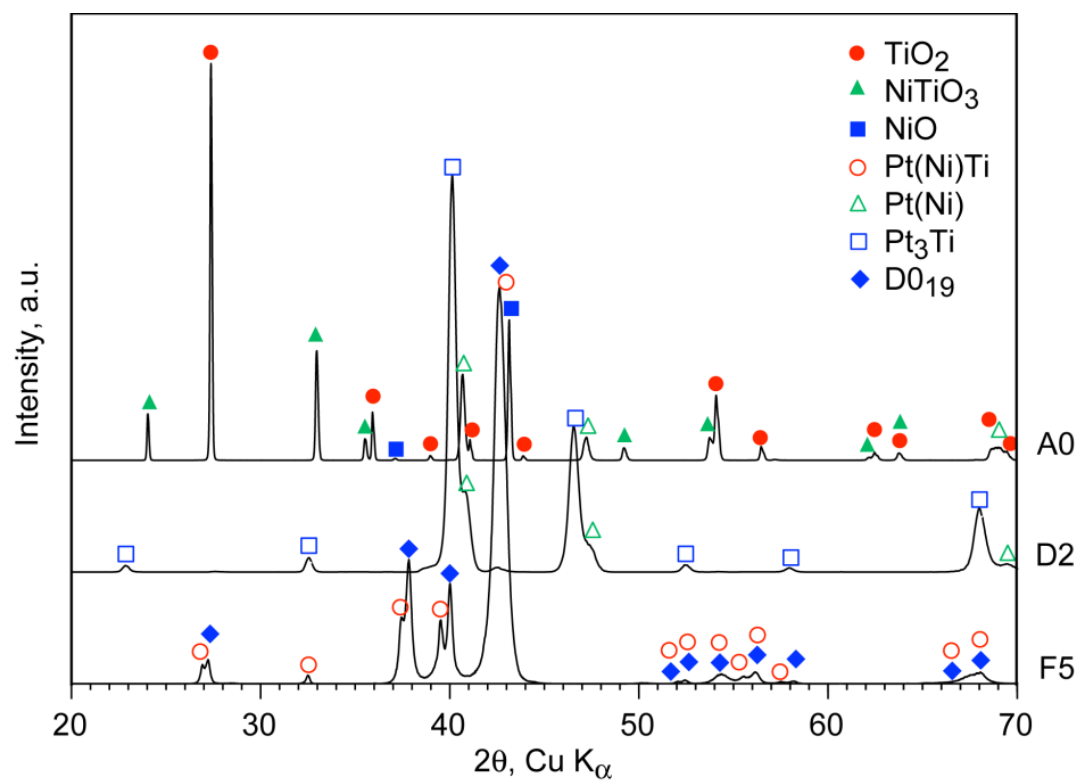

Figure 11.-Representative diffractometer scans of oxidized Ni-30Pt-50Ti surface after $100 \mathrm{hr}$ oxidation at $700{ }^{\circ} \mathrm{C}$. Sequential tapered polishing bands show patterns for external $\mathrm{TiO}_{2}$ and $\mathrm{NiTiO}_{3}$ scale phases, then $\mathrm{Pt}(\mathrm{Ni})$ and $\mathrm{Pt}_{3} \mathrm{Ti}$ depletion zone phases, and finally $\mathrm{Pt}(\mathrm{Ni}) \mathrm{Ti}$ and $\mathrm{DO}_{19}$ substrate metal phases. (From Table 5, A0 refers to no polishing, D2 is the fourth band in second polishing sequence, and F5 for final polishing to substrate).

Taper section scale phases Ni30Pt50Ti, $700{ }^{\circ} \mathrm{C}, 100 \mathrm{hr}$ oxidation

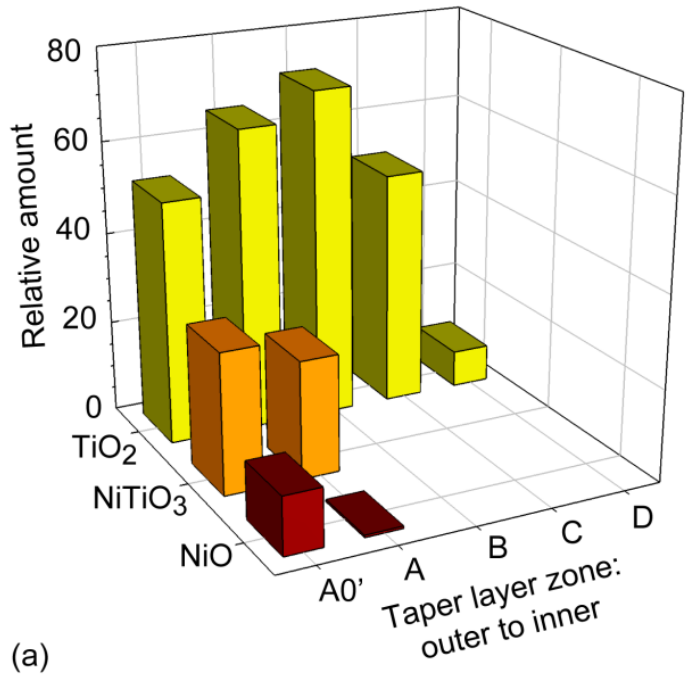

Taper section metallic layer phases $\mathrm{Ni} 30 \mathrm{Pt} 50 \mathrm{Ti}, 700^{\circ} \mathrm{C}, 100 \mathrm{hr}$ oxidation

(b)

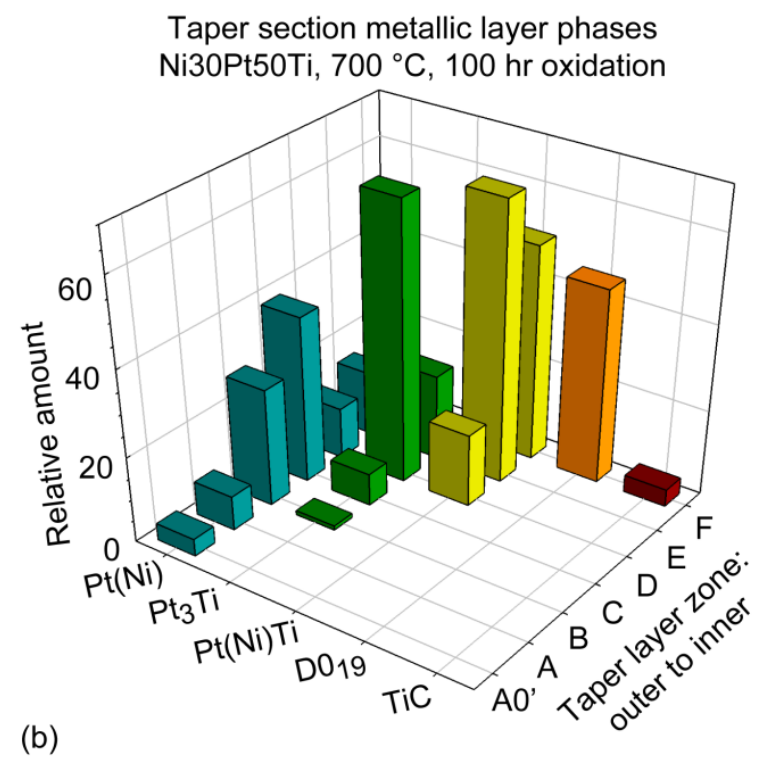

Figure 12.-Trends in semi-quantitative (a) scale and (b) depletion zone phase content from XRD scans of taper section bands (Ni30Pt50Ti after $100 \mathrm{hr}, 700{ }^{\circ} \mathrm{C}$ oxidation). 
TABLE 5.-SEMI-QUANTITATIVE ESTIMATE OF PHASES IN TAPER SECTION BANDS

Ni-30PT-50Ti, OXIDIZED AT $700{ }^{\circ} \mathrm{C}, 100 \mathrm{HR}$

\begin{tabular}{|c|c|c|c|c|c|c|c|c|c|}
\hline $\begin{array}{l}\text { layer, } \\
\text { zone }\end{array}$ & $\begin{array}{c}\Delta \mathrm{W} / \mathrm{A} \\
\mathrm{mg} / \mathrm{cm}^{2}\end{array}$ & $\mathrm{TiO}_{2}$ & $\mathrm{NiO}$ & $\mathrm{NiTiO}_{3}$ & $\mathrm{Pt}(\mathrm{Ni})$ & $\mathrm{Pt}_{3} \mathrm{Ti}$ & PtTi & $\mathrm{DO}_{19}$ & TiC \\
\hline A0 & 0.00 & 49 & 14 & 32 & 4 & & & & \\
\hline A1 & 0.04 & 56 & 11 & 29 & 4 & & & & \\
\hline A2 & 1.58 & 64 & 2 & 27 & 7 & & & & \\
\hline B2 & 1.58 & 75 & & & 23 & 2 & & & \\
\hline $\mathrm{C} 2$ & 1.58 & 51 & & & 40 & 9 & & & \\
\hline D2 & 1.58 & 10 & & & 24 & 64 & 6 & & \\
\hline E2 & 1.58 & & & & 15 & 20 & 65 & & \\
\hline A3 & 2.24 & 67 & 0 & 24 & 9 & & & & \\
\hline B3 & 2.24 & 68 & & & 32 & 1 & & & \\
\hline C3 & 2.24 & 51 & & & 38 & 11 & & & \\
\hline D3 & 2.24 & 6 & & & & 66 & 28 & & \\
\hline E3 & 2.24 & & & & & & 58 & 42 & \\
\hline $\mathrm{F} 4$ & 12.76 & & & & & & 52 & 43 & 5 \\
\hline F5 & 59.65 & & & & & & 49 & 48 & 3 \\
\hline $\mathrm{iO}_{2} \mathrm{sc}$ & 3.79 & & & & & & & & \\
\hline
\end{tabular}

\section{Cross-Sectional SEM of Ni-30Pt-50Ti}

For reference, the various other features highlighted below are matched with corresponding XRD phase analyses of the taper section in Table 4. The EDS spectra in Figures 13 to 15 correspond to various points labeled in the scale cross section of Figure 10. The spectra of Figure 13 indicate a small amount of $\mathrm{NiO}$, more $\mathrm{NiTiO}_{3}$, and the remainder being $\mathrm{TiO}_{2}$ for points \#1, 2, and 3 in Figure 10, i.e., the intermingled light, gray, and dark scale phases, respectively, with an enlarged example shown in the inset. Spectra from the next layer, Figure 14, indicate basically a dark $\mathrm{TiO}_{2}$ matrix (point \#5), with bright, Ptrich dispersed submicron metal particles and coarser, elongated fingers (point \#4). The high carbon peak here suggests some contribution from TiC particles, not readily distinguished. The Pt fingers are then ultimately connected to a continuous, $3-\mu \mathrm{m}$, nearly pure, Pt metal depletion zone (point \#6). Spectra for the diffusion affected substrate, shown in Figure 15, shows two similar Pt(Ti)-rich gray (point \#7) and light (point \#8) metal regions, with dark $\mathrm{Ti}(\mathrm{Pt})-\mathrm{C}$ dispersed particles (point \#9). Finally, the interior of the sample, shown in Figure 16, displays a grain boundary necklace of a white phase with a light gray grain interior. These both produce similar Pt(Ti) EDS spectra, Figure 17, and very low Ni content in the white phase. The very dark particles reflect the dispersed TiC phase identified in the as-received material, but again with only a moderately enhanced carbon peak relative to the other spectra. There is also a dark gray Widmanstatten-type morphology that appears to be associated with the bright grain boundary phase. This gray acicular phase was not analyzed. 


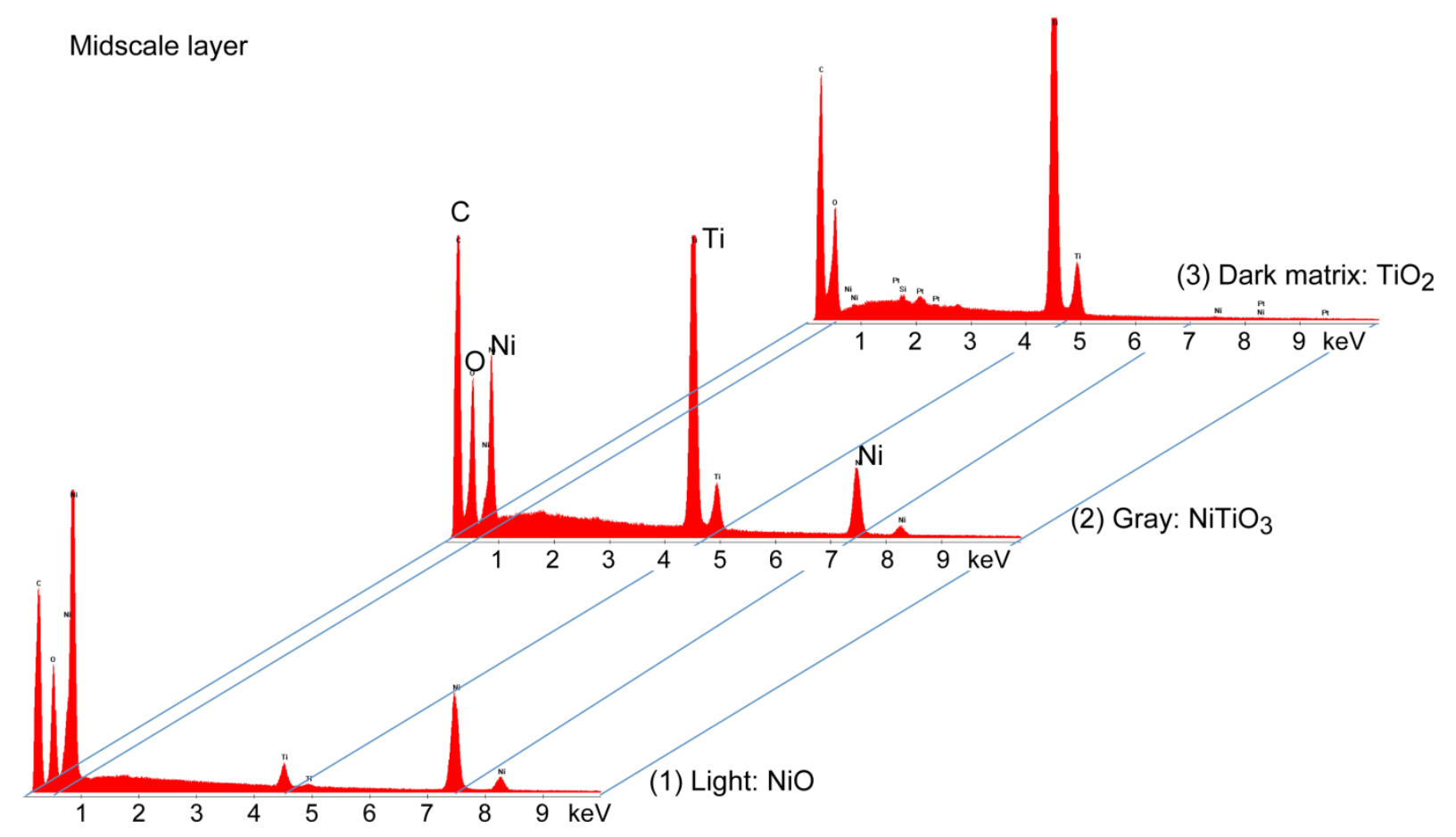

Figure 13.-SEM/EDS spectra corresponding to outer scale features 1 to 3 from Figure 10 (Ni30Pt50Ti after $100 \mathrm{hr}$ $700^{\circ} \mathrm{C}$ oxidation).

Subscale layer and depletion zone

s.

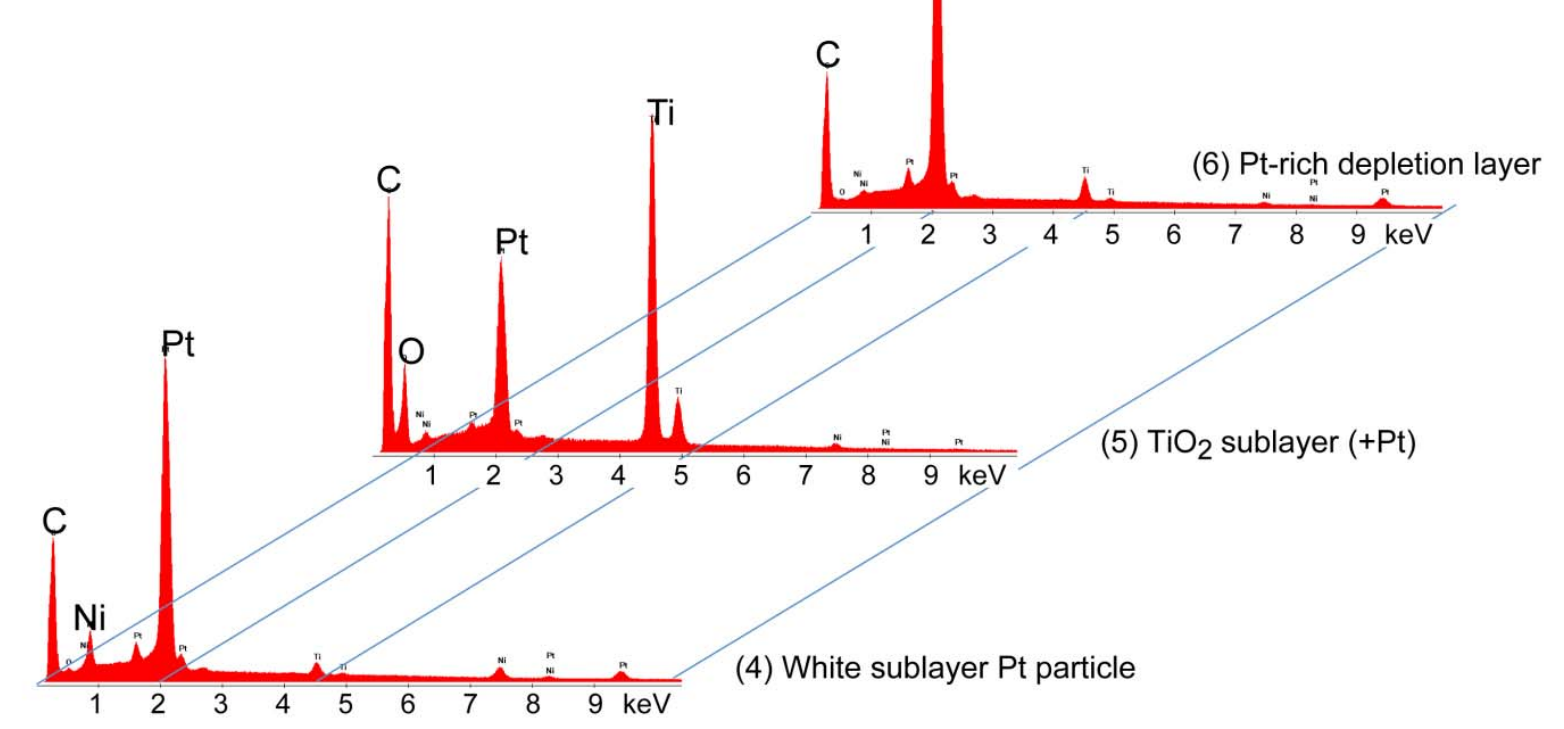

Figure 14.-SEM/EDS spectra corresponding to subscale features 4 to 6 from Figure 10 (Ni30Pt50Ti after $100 \mathrm{hr}$ $700^{\circ} \mathrm{C}$ oxidation). 


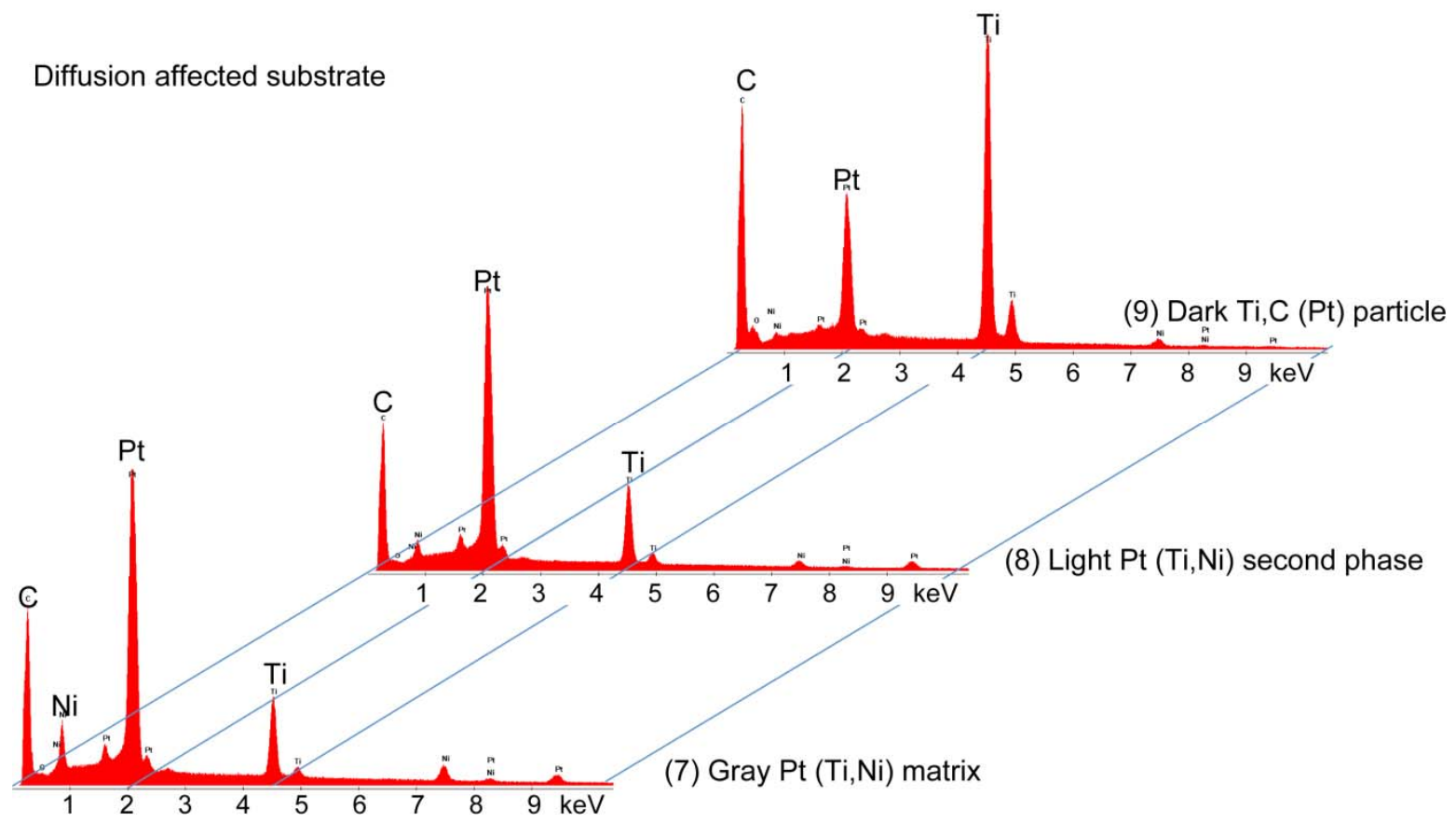

Figure 15.-SEM/EDS spectra corresponding to near substrate features 7 to 9 from Figure 10 (Ni30Pt50Ti after $100 \mathrm{hr} 700^{\circ} \mathrm{C}$ oxidation).

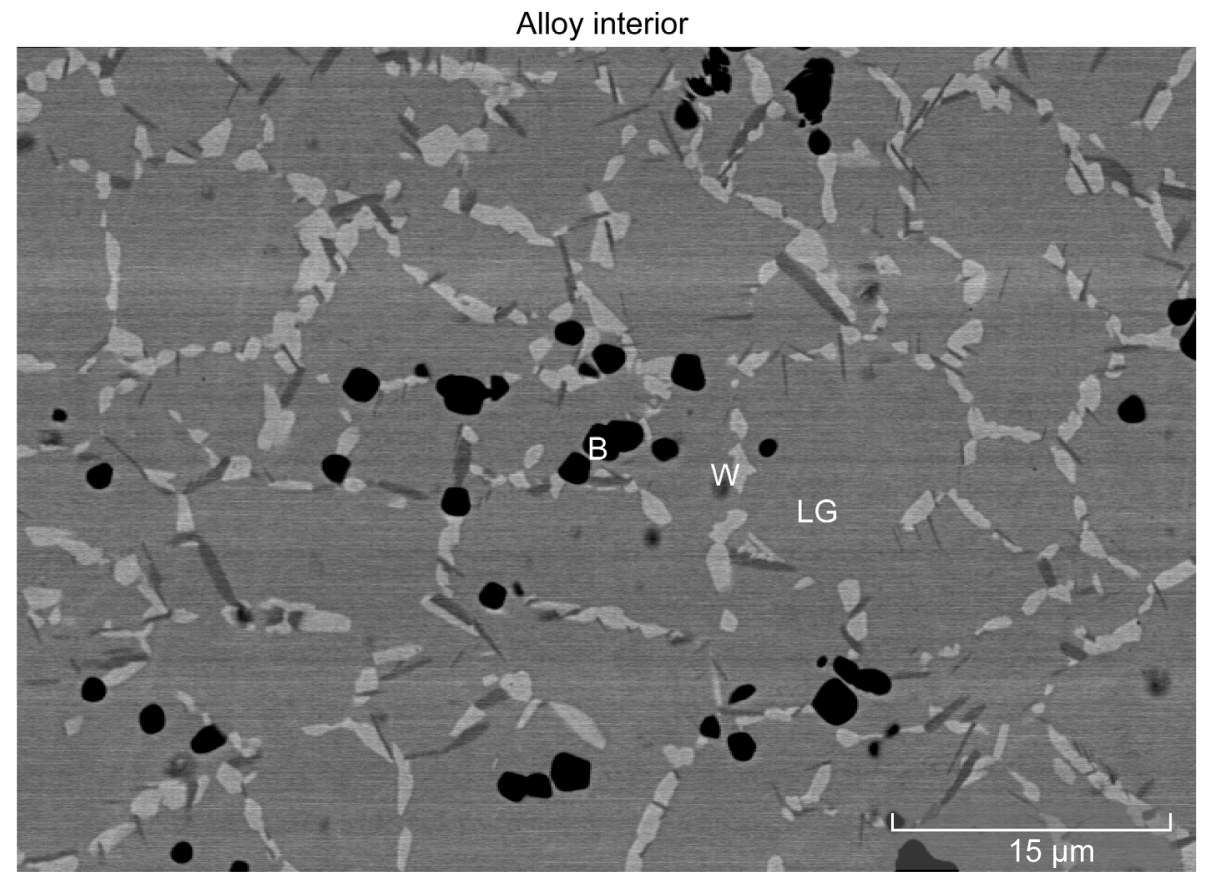

Figure 16.-Grain boundary-decomposition phase in unaffected substrate midsection. 


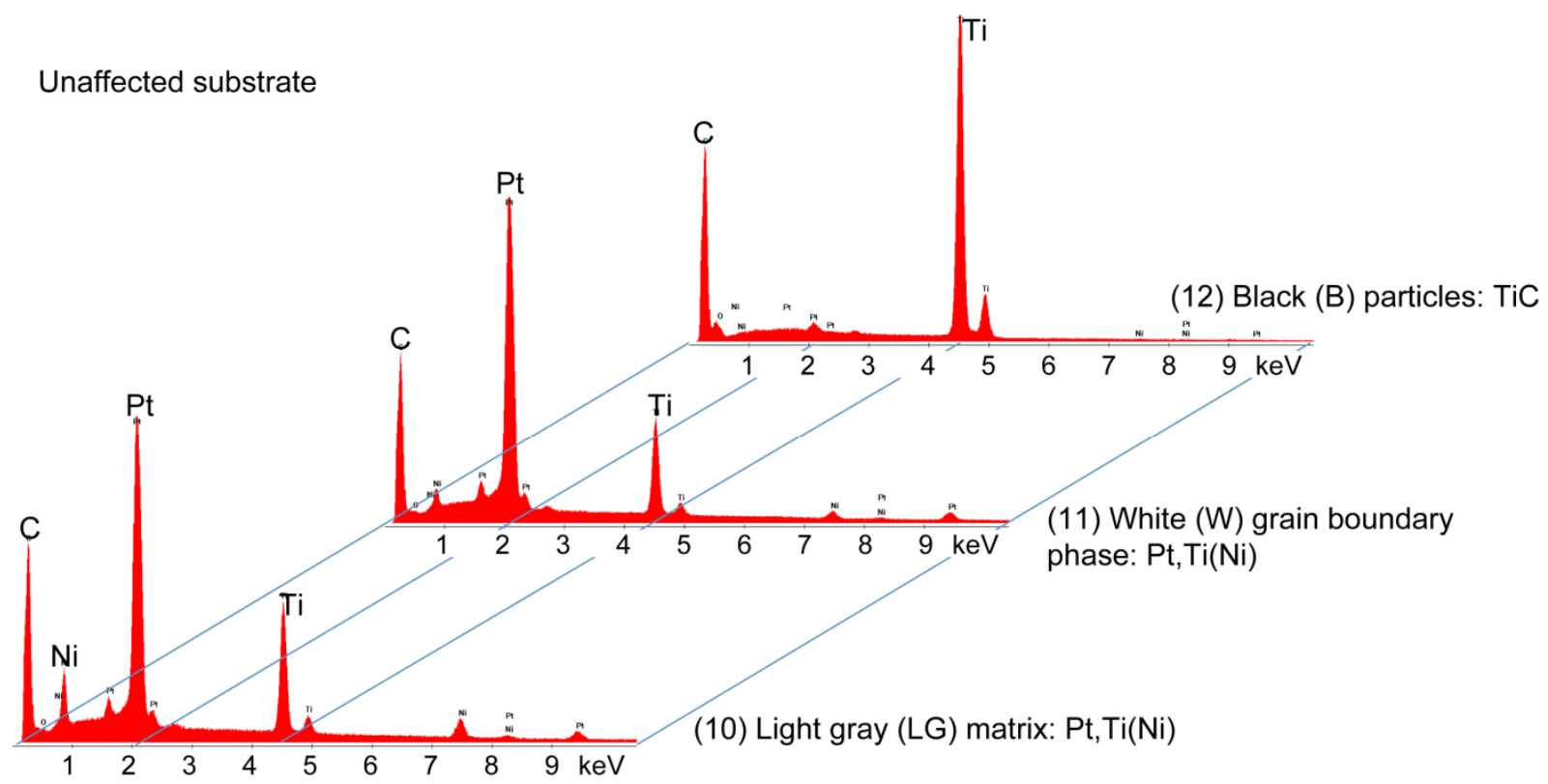

Figure 17.-SEM/EDS spectra corresponding to subscale features 10 to 12 (LG grain center, W grain boundary, B particle) from Figure 16 (Ni30Pt50Ti after $100 \mathrm{hr}, 700^{\circ} \mathrm{C}$ oxidation).

\section{Plan View of Surface Scales}

\section{Ni49Ti}

Given this overview, we now proceed to the characterization of the various detailed features that present themselves at the surface in plan view. An overview of the surface structure for scales formed on Ni49Ti by oxidation at 600 to $900{ }^{\circ} \mathrm{C}$ is presented in Figure 18, showing the strong effect of oxidation temperature. Here angular, often striated and faceted crystals were easily discerned for the 600 to $800{ }^{\circ} \mathrm{C}$ samples, with a grain size clearly increasing with temperature. These are hallmark characteristics of outward $\mathrm{TiO}_{2}$ rutile scale growth. For the sake of clarity, these are shown at higher magnification for $600{ }^{\circ} \mathrm{C}$ oxidation, Figure 19 , along with a relatively clean Ti, O spectra. Unfortunately, at $900{ }^{\circ} \mathrm{C}$, spalling was so prevalent that no area of intact scale surface could be located, and the exact scale-gas surface is not represented in Figure 18.

Thus a feature common to the scales formed above $700{ }^{\circ} \mathrm{C}$ is the appearance of fracture ledges and plateaus due to complex spall patterns. An example of these is shown in Figures 20(a) and (b) for Ni-49Ti oxidized at $700{ }^{\circ} \mathrm{C}$ for $100 \mathrm{hr}$. Here three layers and two fracture ledges are revealed, with the top layer representing the gas surface. EDS spectra for the top fracture ledge indicates pure $\mathrm{TiO}_{2}$ (Fig. 21(a)). Within this ledge, some brighter particles yield a Ni-Ti-O rich chemistry, probably indicating $\mathrm{NiTiO}_{3}$ (Fig. 21(b)). Below this, the sharp, chard-like crystals yield a Ti-Fe-O rich chemistry (with some Ni), Figure 21(c), and probably correspond to the Fe-rich, spearhead-like crystals identified in cross-section Figure 5. EDS suggests this may be a $\mathrm{FeTiO}_{3}$ illmenite phase, however only $\mathrm{Fe}_{3} \mathrm{O}_{4}$ was detected by XRD in the serial sectioning study. Finally the lower layer yields a spectrum Figure 21(d) identical to the white particles in the ledge, namely a Ni-Ti-rich oxide (with some Fe), presumably $\mathrm{NiTiO}_{3}$ again.

After $800^{\circ} \mathrm{C}$ oxidation, some fracture ledge features, Figure 22, are characterized by EDS as pure $\mathrm{TiO}_{2}$ and as a Ti-Fe-Ni-rich oxide, somewhat suggestive of the Fe-rich needles discussed above. Another example of this combination is presented in Figure 23, for what appears to be a porous interface of a spalled layer. Finally, after $900{ }^{\circ} \mathrm{C}$ oxidation, some globular features revealed in fracture plateaus, Figure 24, appear to be dispersed metallic Ni particles (X) in a matrix of essentially pure $\mathrm{TiO}_{2}(\mathrm{Y})$, similar to the dispersed sublayer particles in the $700{ }^{\circ} \mathrm{C}$ cross-section, Figure 5. Another area, Figure 25, indicates a dispersion of Ti-Ni-O rich particles (X), consistent with $\mathrm{NiTiO}_{3}$, in a matrix of $\mathrm{TiO}_{2}(\mathrm{Y})$. 
$\mathrm{Ni49Ti}$
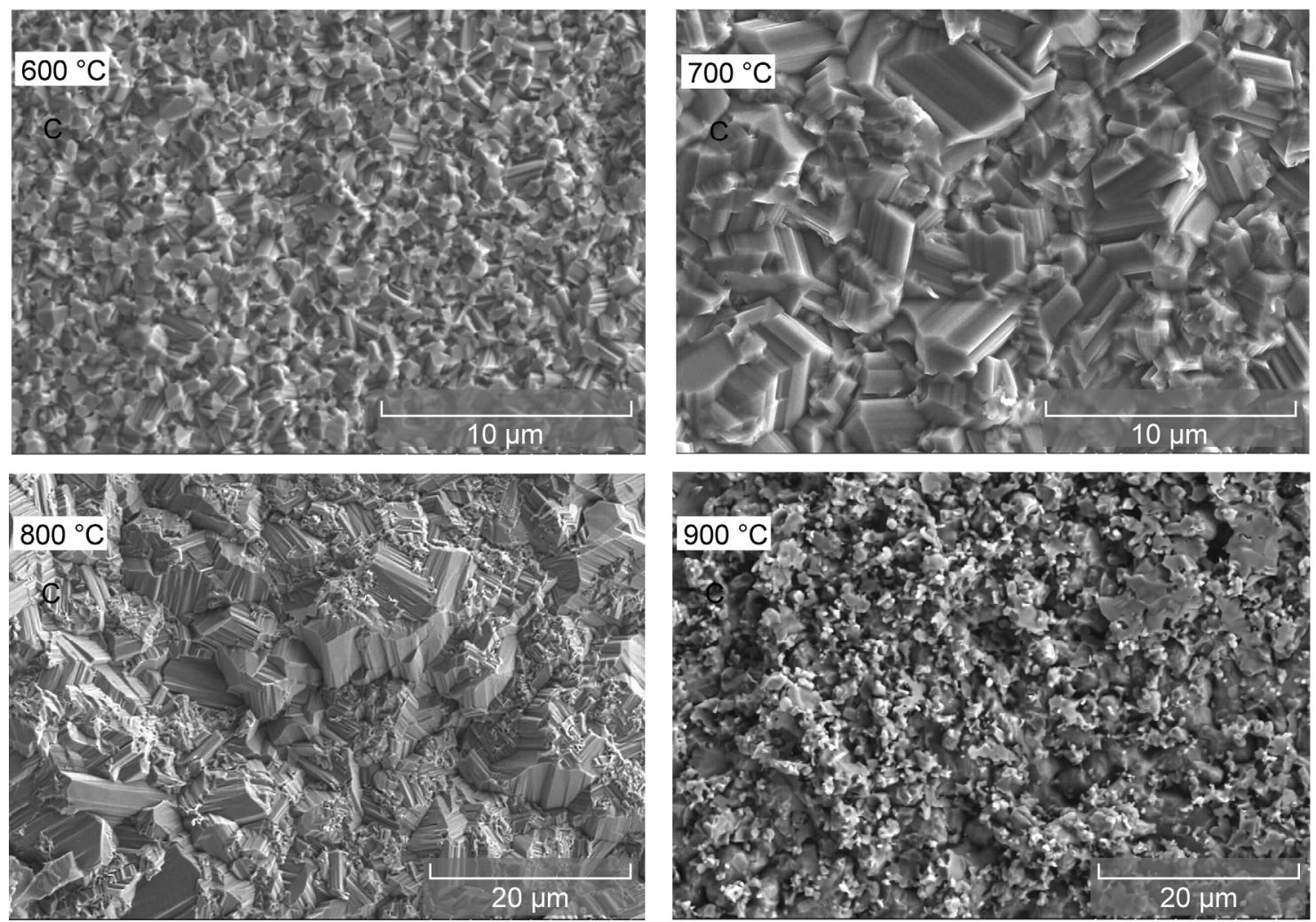

Figure 18.-Surface scale features of Ni49Ti after oxidation at $600,700,800$, and $900{ }^{\circ} \mathrm{C}$.

Ni49Ti $600{ }^{\circ} \mathrm{C}$; bright, large crystals
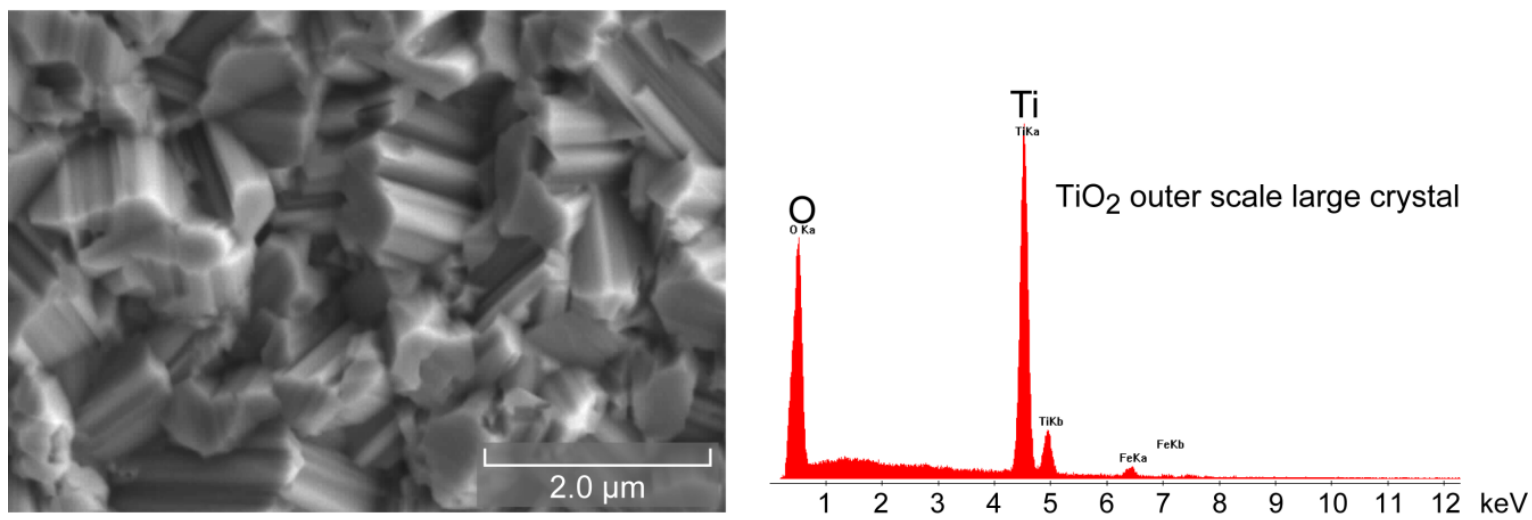

Figure 19.-Detail of stepped facets of $\mathrm{TiO}_{2}$ grains in the scale (Ni49Ti after $100 \mathrm{hr}$ oxidation at $600{ }^{\circ} \mathrm{C}$ ). 
Ni49Ti: $700{ }^{\circ} \mathrm{C} / 100$ hr/air
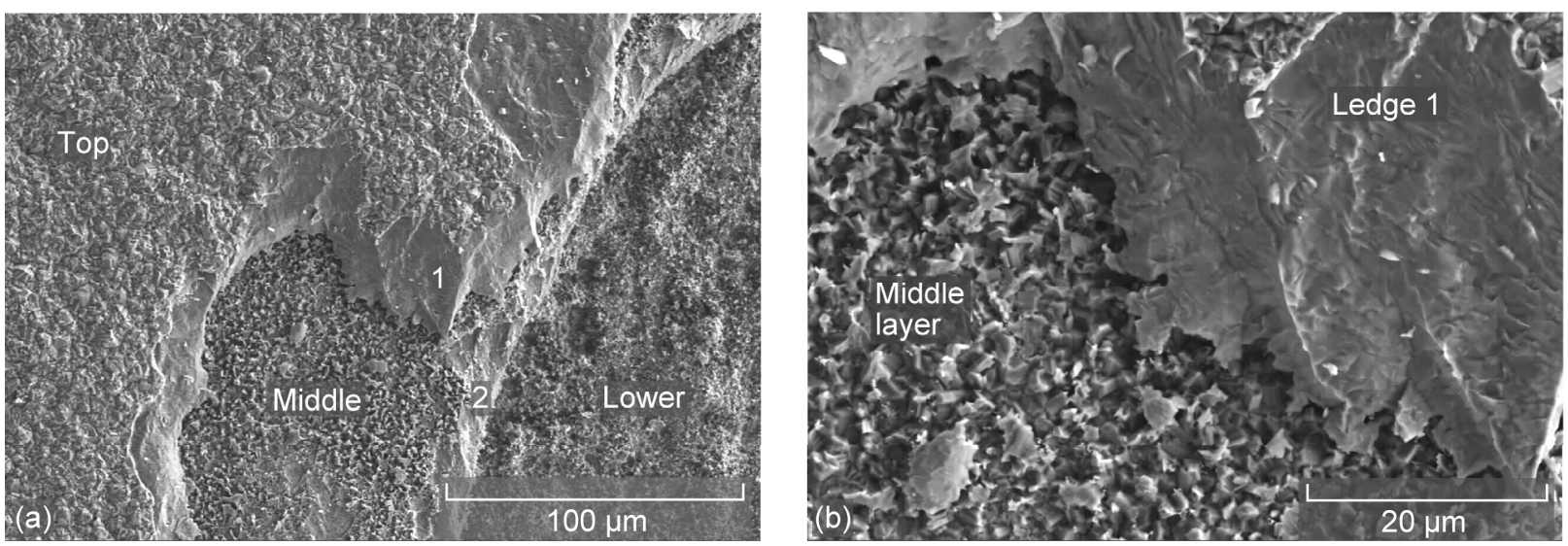

Figure 20.- Overview and detail of scalloped spall ledges in surface scale (Ni49Ti after $100 \mathrm{hr}$ oxidation at $700{ }^{\circ} \mathrm{C}$ ).

Ni49Ti; $700{ }^{\circ} \mathrm{C} / 100 \mathrm{hr}$

$\mathrm{TiO}_{2}$ ledge + Ni-rich particles; middle Fe-rich crystals; Ni-rich lower layer (a)

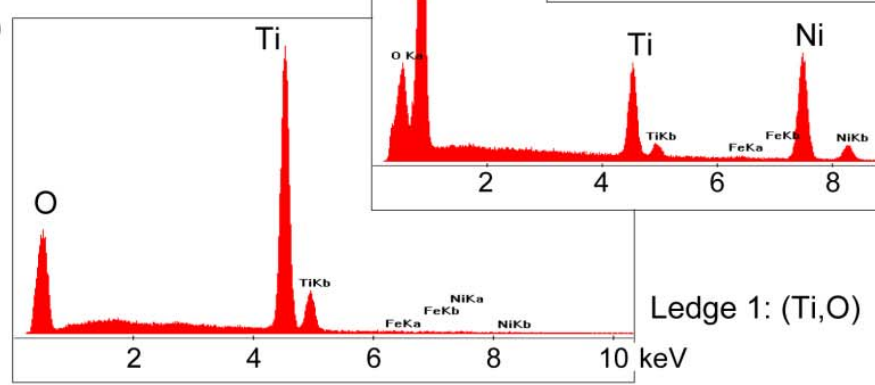

(d)

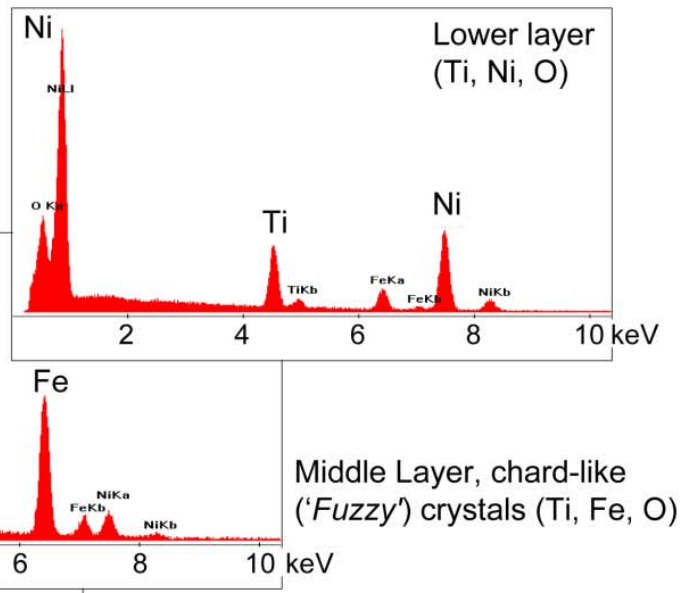

White particles in ledge 1

$(\mathrm{Ti}, \mathrm{Ni}, \mathrm{O})$

Figure 21.-SEM/EDS spectra of $\mathrm{TiO}_{2}$ surface, Ni-rich particles in fracture ledge, Fe-rich crystals in exposed middle layer, and Ni-rich innermost layer, from Figure 16. 
Ni49Ti: $800{ }^{\circ} \mathrm{C} / 100 \mathrm{hr}$; scale fracture features
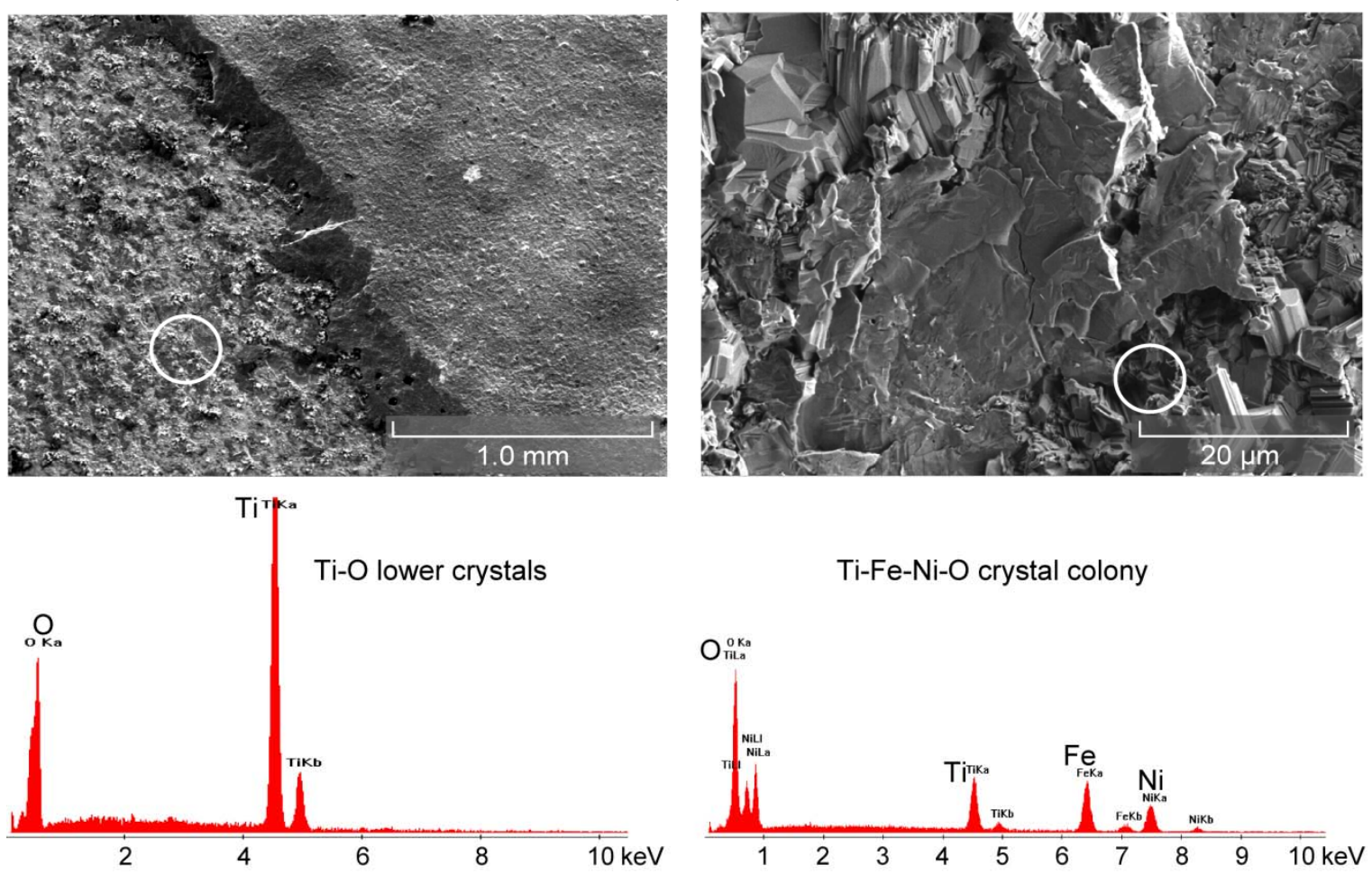

Ti-Fe-Ni-O crystal colony

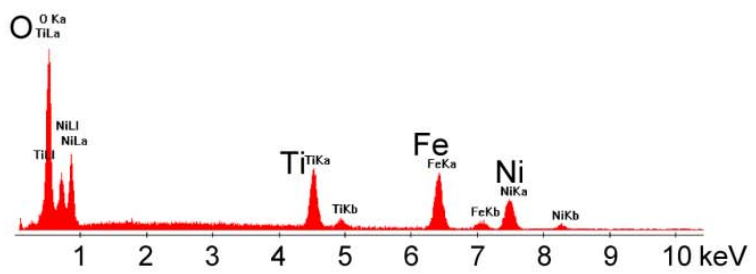

Figure 22.-Large plateaus of intact $\mathrm{TiO}_{2}$ and spalled regions exposing Ti-Ni-Fe-rich oxide particles (Ni49Ti after $100 \mathrm{hr}$ oxidation at $800^{\circ} \mathrm{C}$ ).

Ni49Ti: $800{ }^{\circ} \mathrm{C} / 100 \mathrm{hr}$; porous inner layer

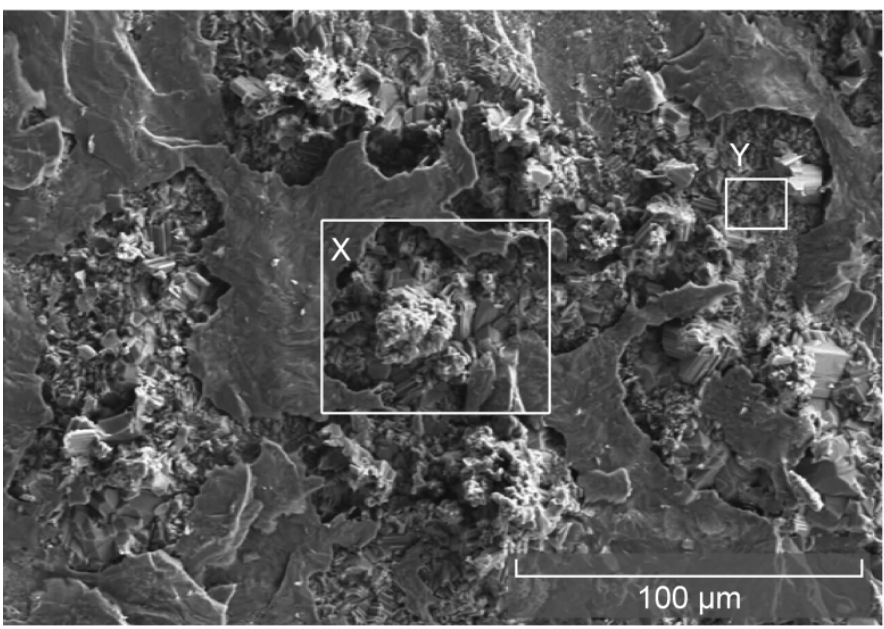

$\mathrm{X}: \mathrm{TiO}_{2}$

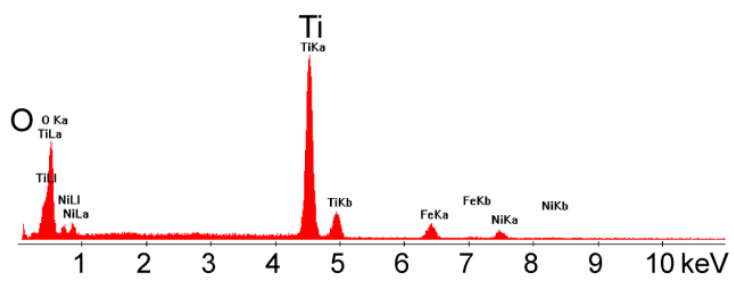

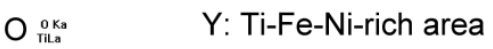

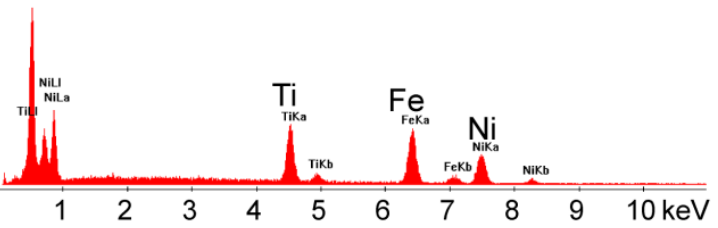

Figure 23.-Spalled regions exposing porous inner layer showing similar $\mathrm{TiO}_{2}$ and $\mathrm{Ti}-\mathrm{Ni}$-Fe-rich oxide chemistry (Ni49Ti after $100 \mathrm{hr}$ oxidation at $800^{\circ} \mathrm{C}$ ). 

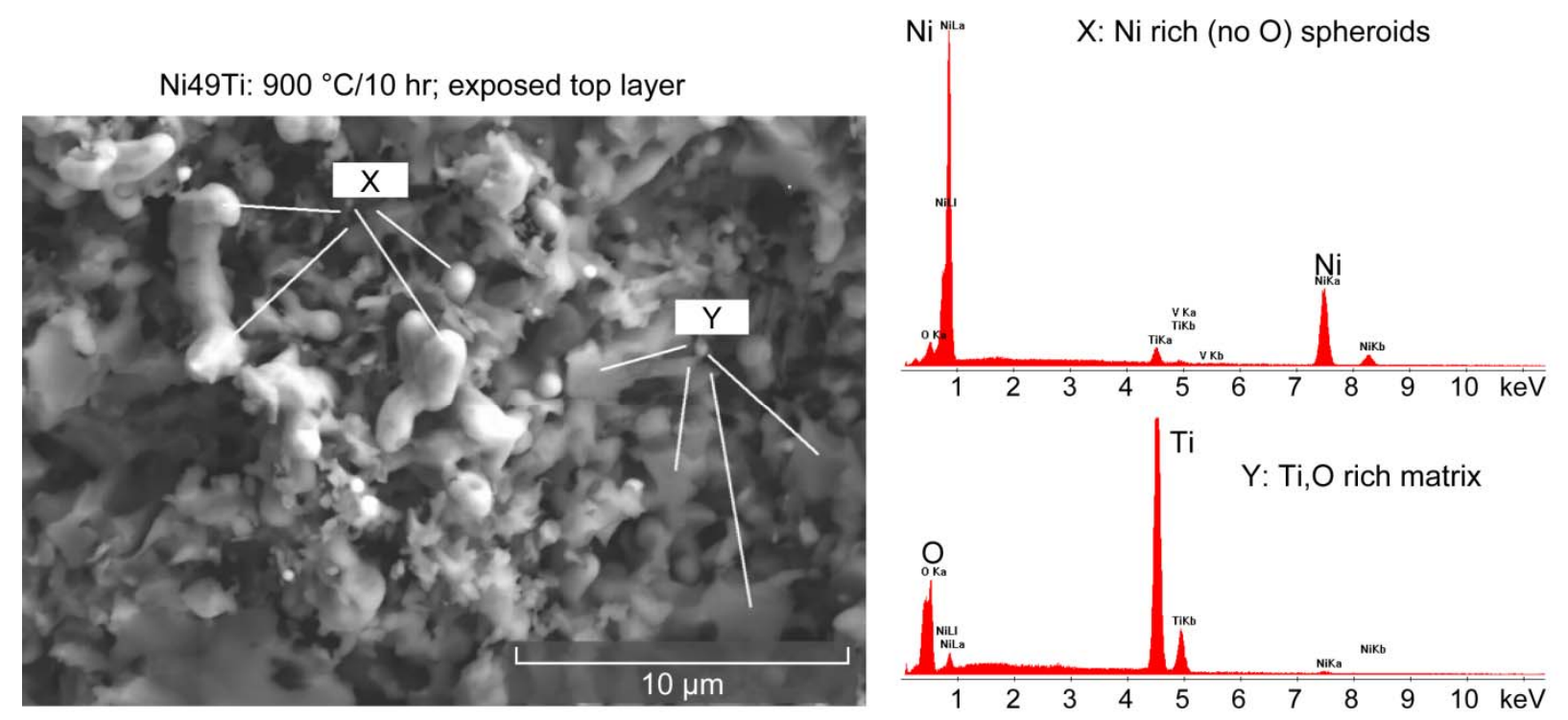

Figure 24.-Spheroidal metallic Ni particles in a $\mathrm{TiO}_{2}$ scale matrix at the exposed outer layer (Ni49Ti after $10 \mathrm{hr}$ oxidation at $\left.900^{\circ} \mathrm{C}\right)$.

Ni49Ti: $900^{\circ} \mathrm{C} / 10 \mathrm{hr}$; lower oxide layer

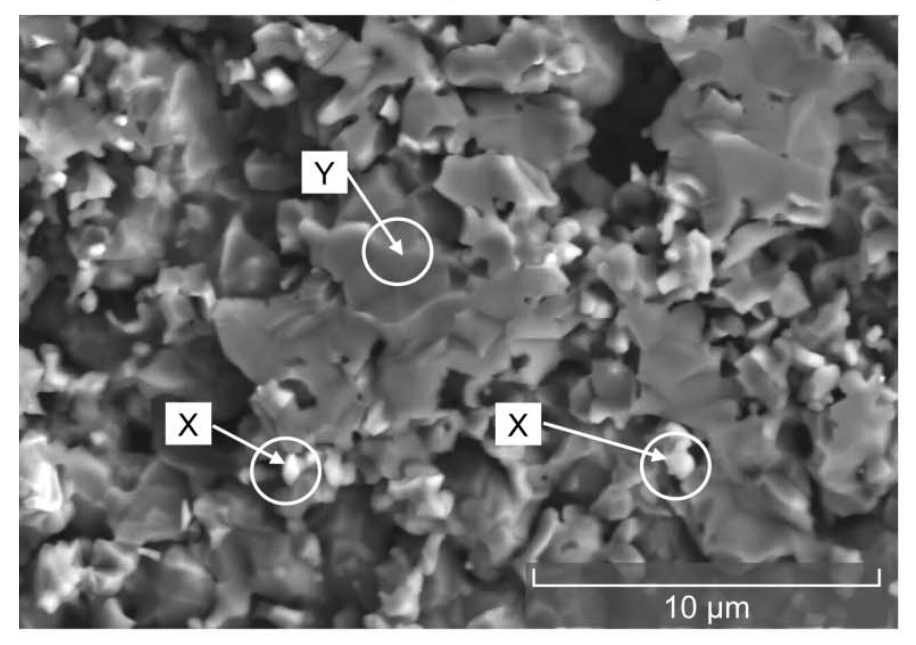

Figure 25.-Ti-Ni-rich oxide particles in a $\mathrm{TiO}_{2}$ scale matrix at the lower inner layer (Ni49Ti after $10 \mathrm{hr}$ oxidation at $\left.900{ }^{\circ} \mathrm{C}\right)$.

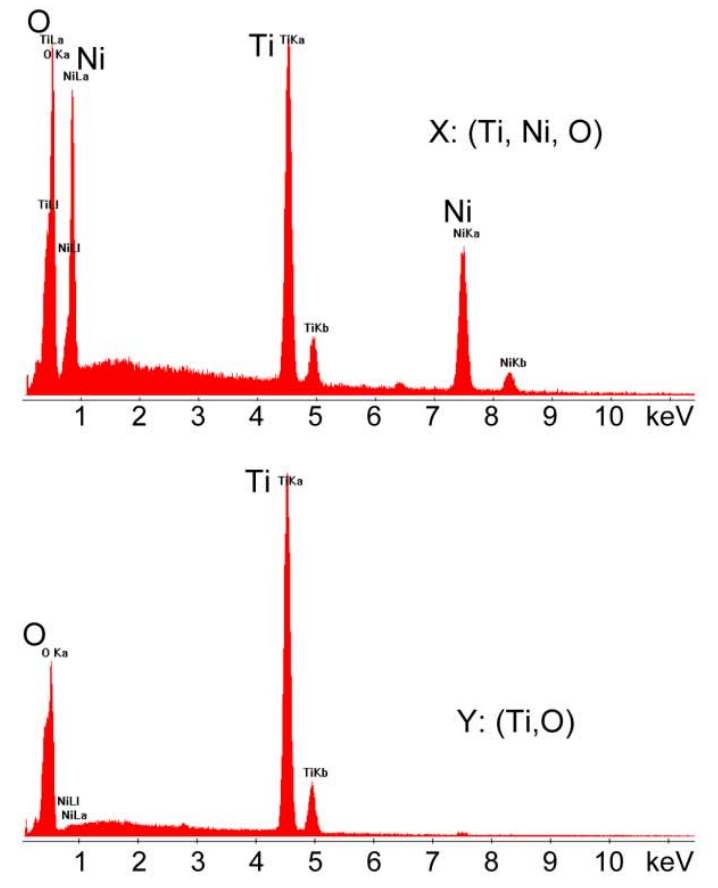




\section{Ni-30Pt-50Ti}

An overview for scales formed on Ni-30Pt-50Ti by oxidation at 600 to $900{ }^{\circ} \mathrm{C}$ is presented in Figure 26. Here colonies or outcroppings of the faceted and striated $\mathrm{TiO}_{2}$ grains are seen as isolated islands on a sea of finer grain, smoother material. The progressive increase in crystal size with temperature is apparent. (However, no unspalled areas showing these features could be located for the $800{ }^{\circ} \mathrm{C}$ sample).

The structure developed at $600{ }^{\circ} \mathrm{C}$ is shown in more detail in Figure 27, and, while both the large (X) and fine grained crystals $(\mathrm{Y})$ are revealed as pure $\mathrm{TiO}_{2}$, a very fine localized dispersion of $\mathrm{Pt}(\mathrm{Ni})$-rich spheroids (Z) was identified by the EDS spectra. At $700{ }^{\circ} \mathrm{C}$, the large faceted crystals (X), Figure 28, are again $\mathrm{TiO}_{2}$, but some finer grain areas (Y) yield EDS spectra most consistent with $\mathrm{NiO}$, as pointed out in Figures 4 and 12 . At $800^{\circ} \mathrm{C}$, multiple levels were revealed, Figure 29, and a fractured plateau reveals a distinct dispersion of bright Pt-rich particles in a matrix of $\mathrm{TiO}_{2}$, Figure 30. This is similar to the dispersion of Pt-rich particles in the $700{ }^{\circ} \mathrm{C}$ cross-section surrounded by $\mathrm{TiO}_{2}$. Finally, at $900{ }^{\circ} \mathrm{C}$, Figure 31, enormous, highly-striated $\mathrm{TiO}_{2}$ crystals are observed. Here even the fine grain external scale, Figure 31(b), appears highly crystallographic and faceted. Lower layers, exposed by spallation, show both cleaved, flat grains (Fig. 32(a)) and filamentary or needle-like features, clustered in parallel colonies (Fig. 32(b)). Both regions of the lower layers are peppered with a fine dispersion of bright particles, presumably Pt-rich metal again. All these regions produced EDS spectra consistent with $\mathrm{TiO}_{2}$ as the primary phase, Figure 33.
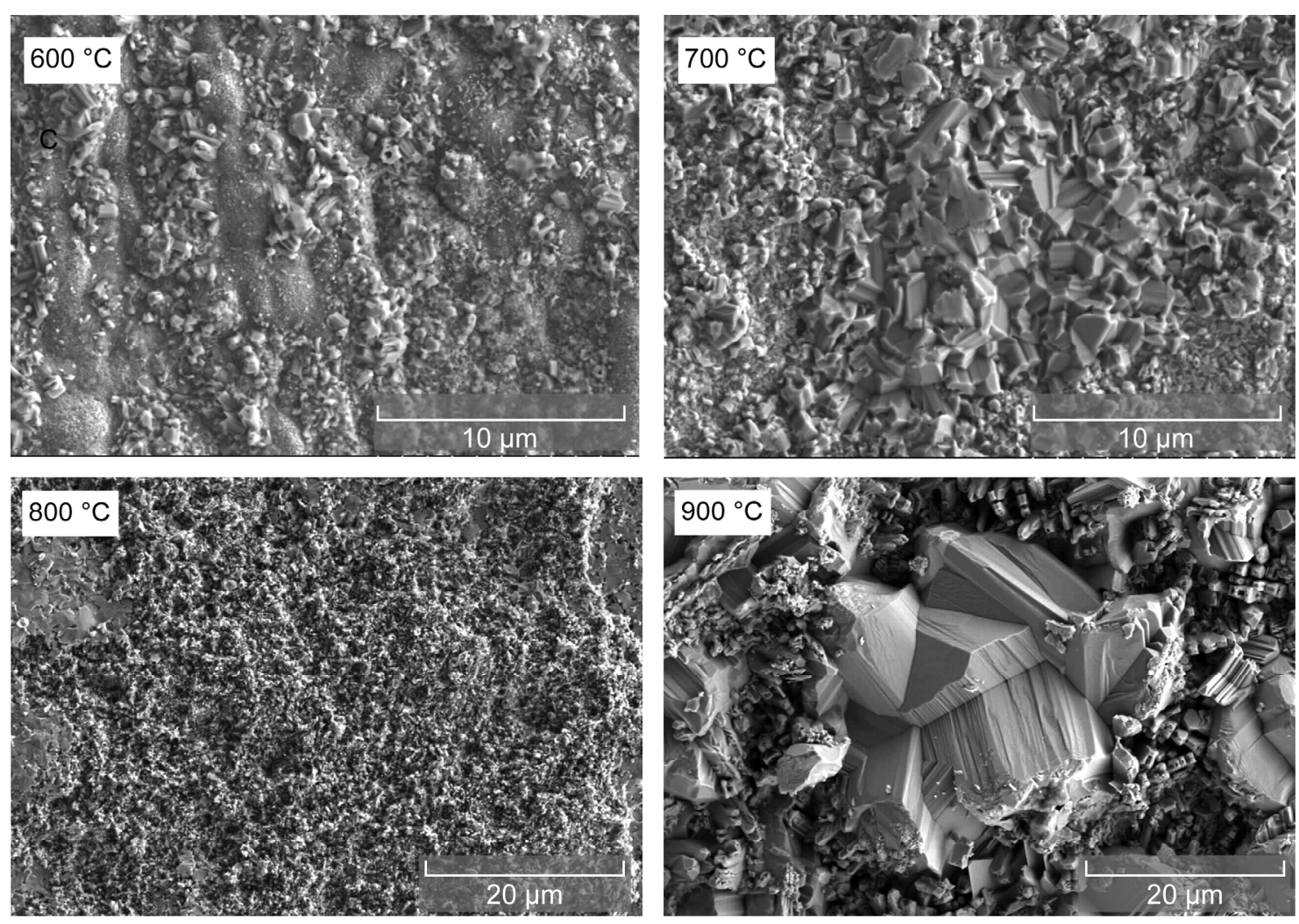

Figure 26.-Duplex grain structure in outer scale layers for Ni30Pt50Ti after oxidation at 600, 700, 800, and $900^{\circ} \mathrm{C}$. 
Ni30Pt50Ti; $600{ }^{\circ} \mathrm{C}$

Duplex terrain: Ti-O fine grain plateau with Pt,Ni-rich particles; coarser Ti-O crystals colonies
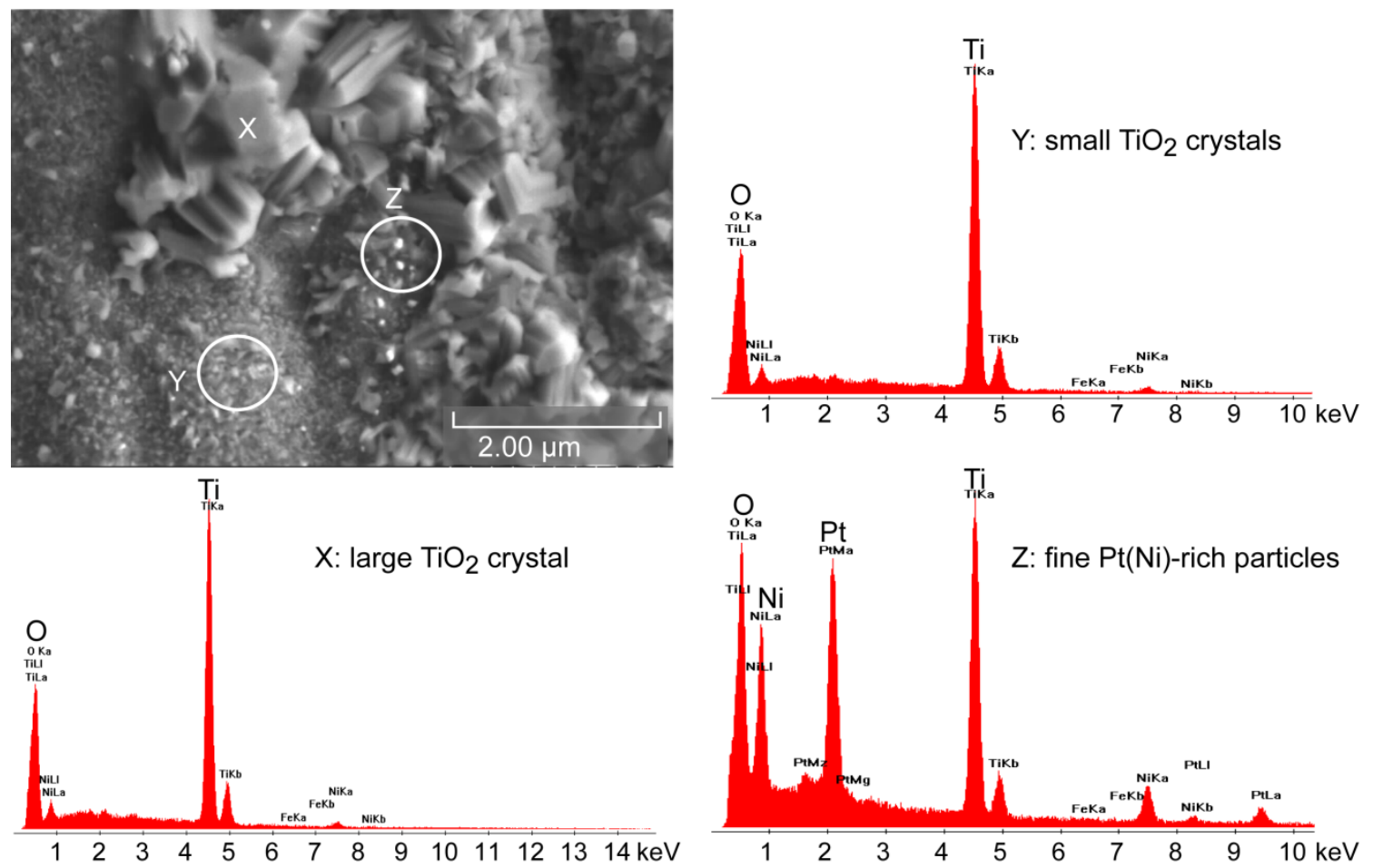

Figure 27.-Coarser faceted and fine grain $\mathrm{TiO}_{2}$ crystals and $\mathrm{Pt}(\mathrm{Ni})$-rich particles on the surface of oxidized Ni30Pt50Ti after $100 \mathrm{hr}$ oxidation at $600{ }^{\circ} \mathrm{C}$.

Ni30Pt50Ti; $700{ }^{\circ} \mathrm{C}$

Duplex terrain: fine grain plateau, coarse crystals colonies and Pt particles

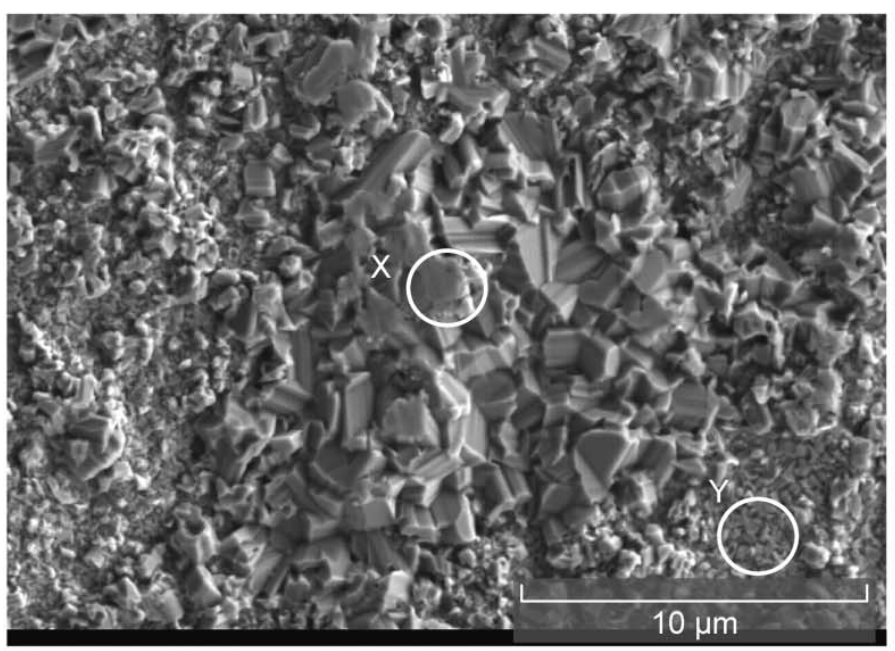

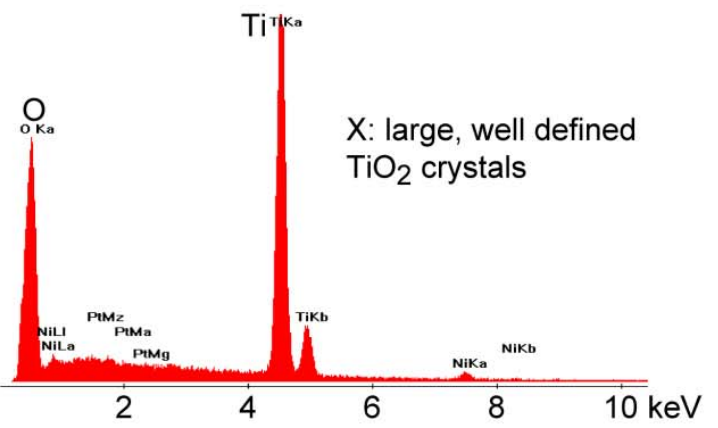

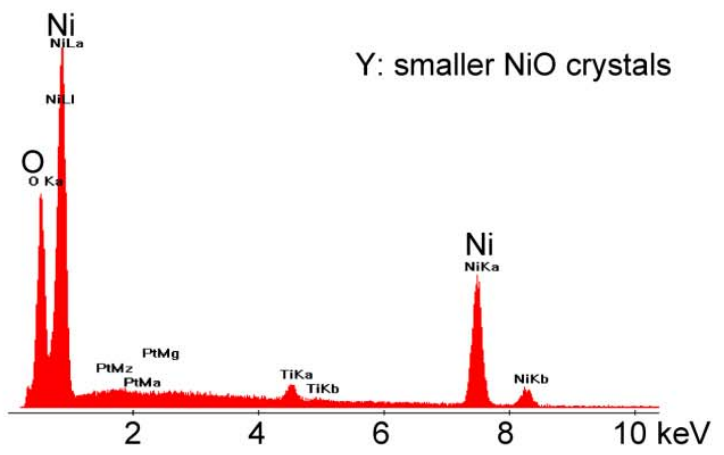

Figure 28.-Duplex grain structure and fine grain Ni-rich oxide on oxidized Ni30Pt50Ti after $100 \mathrm{hr}$ oxidation at $700{ }^{\circ} \mathrm{C}$. 


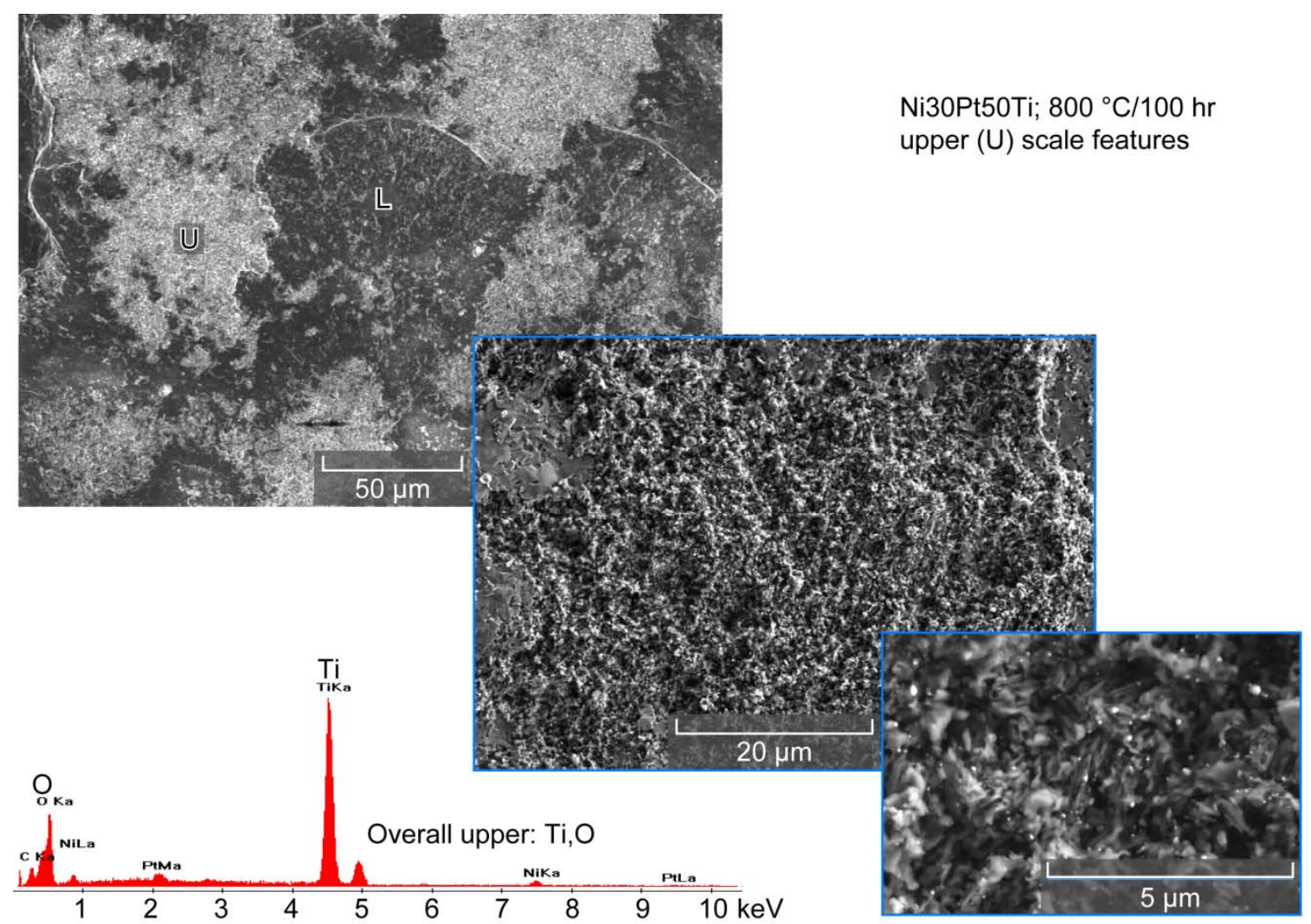

Figure 29.- - Large plateaus of spalled regions and structures at various levels of detail for spalled upper surface of $\mathrm{TiO}_{2}$ scale (Ni30Pt50Ti after $100 \mathrm{hr}$ oxidation at $800^{\circ} \mathrm{C}$ ).

Ni30Pt50Ti; $800{ }^{\circ} \mathrm{C} / 100 \mathrm{hr}$; cleaved lower scale features

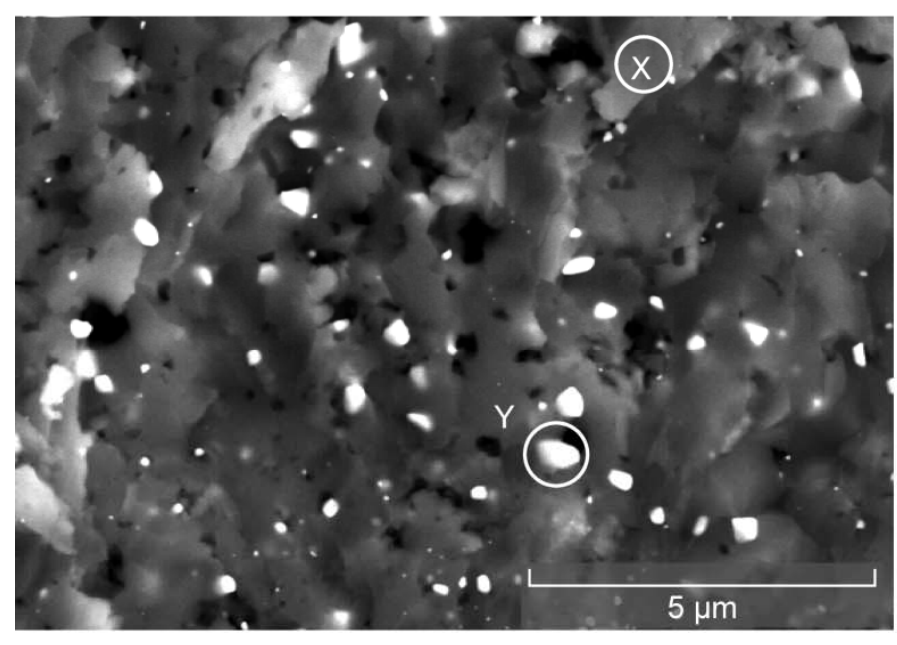

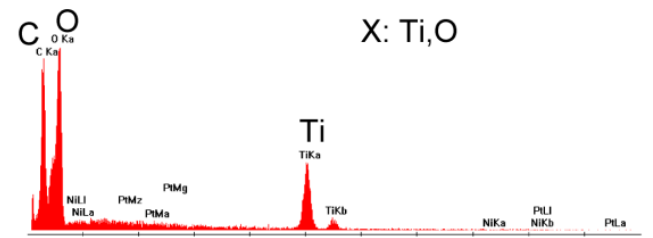

$0.91 .82 .73 .64 .55 .46 .37 .28 .19 .0 \mathrm{keV}$

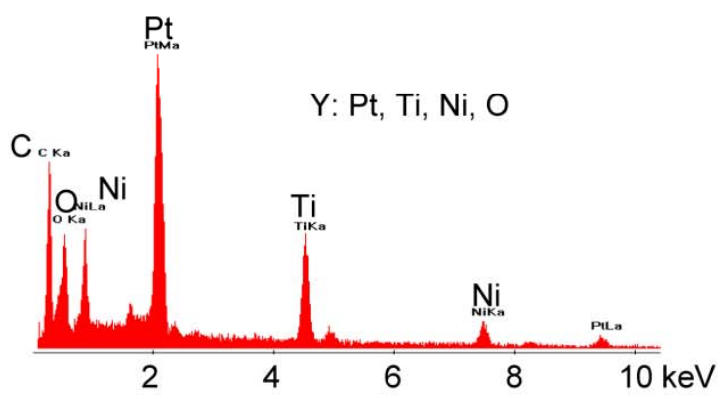

Figure 30.-Cleaved plane in lower scale showing $\mathrm{TiO}_{2}$ matrix with Pt-Ni-rich particles (Ni30Pt50Ti after $100 \mathrm{hr}$ oxidation at $800^{\circ} \mathrm{C}$ ). 

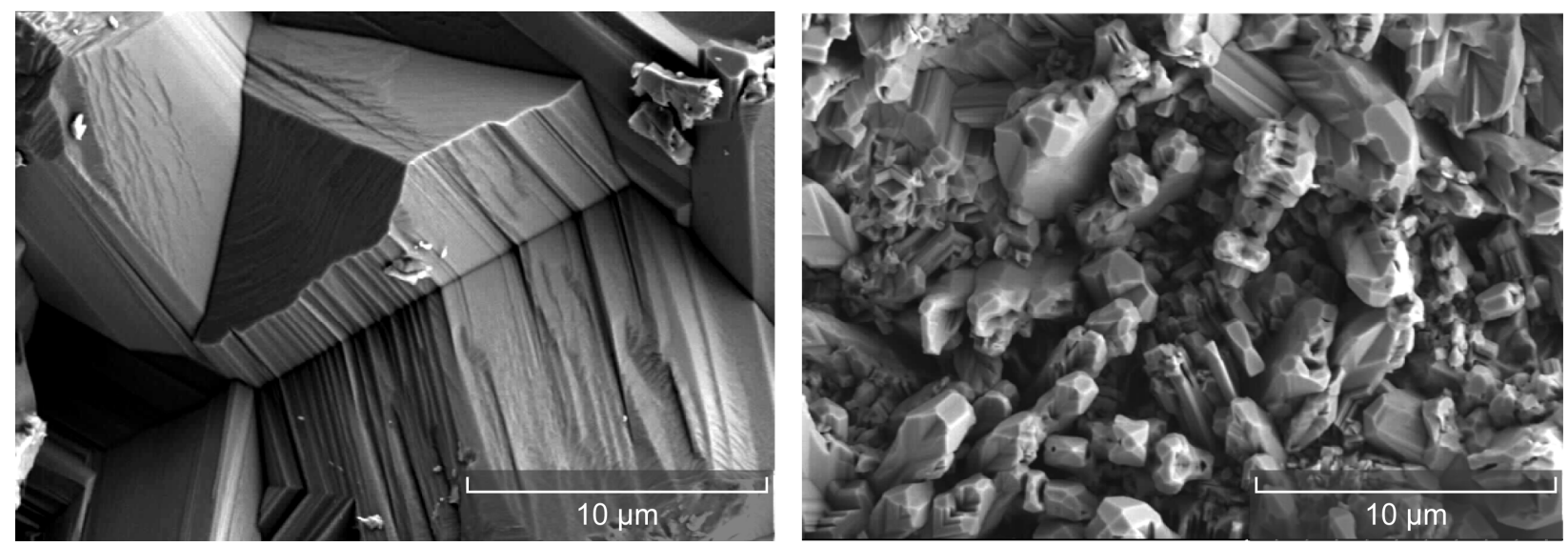

Figure 31.-Highly striated massive crystals and crystallographically faceted fine grain structures (Ni30Pt50Ti after $10 \mathrm{hr}$ oxidation at $900^{\circ} \mathrm{C}$ ).

Ni30Pt50Ti: $900{ }^{\circ} \mathrm{C} /$ lower layer; $10 \mathrm{hr}$
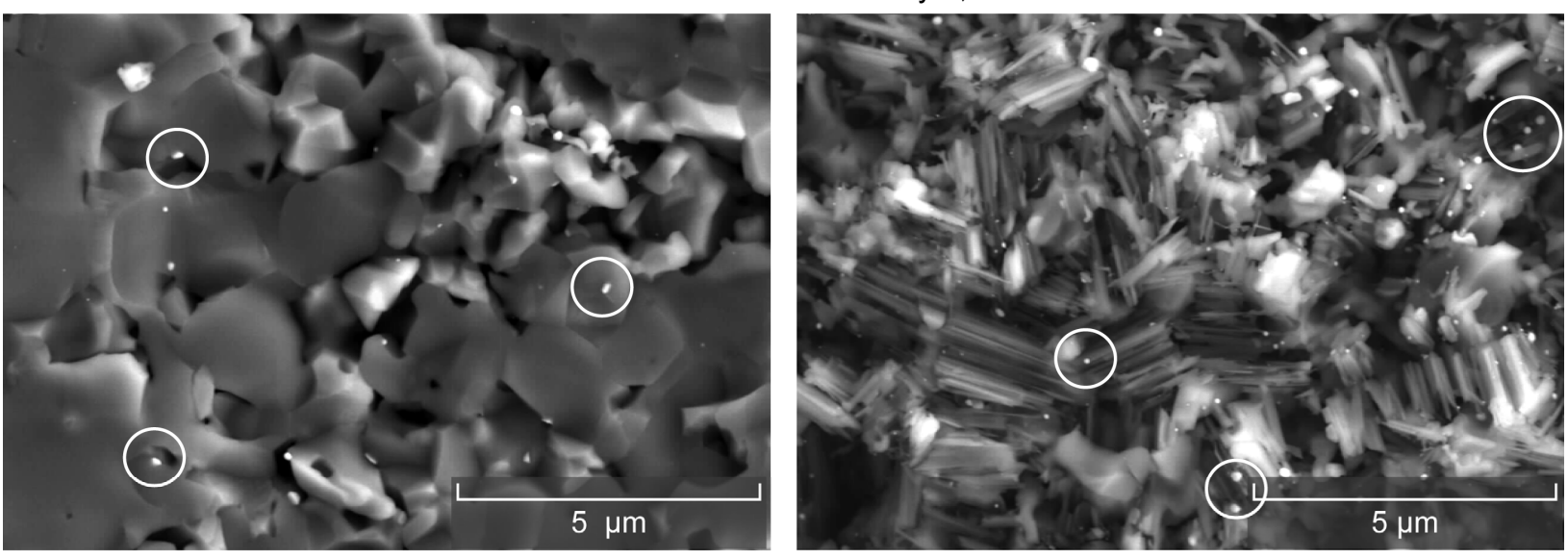

Figure 32.-Cleaved and striated fibrous grains and fine spheroidal particles in spalled region of scale formed on Ni30Pt50Ti after $10 \mathrm{hr}$ oxidation at $900{ }^{\circ} \mathrm{C}$. 


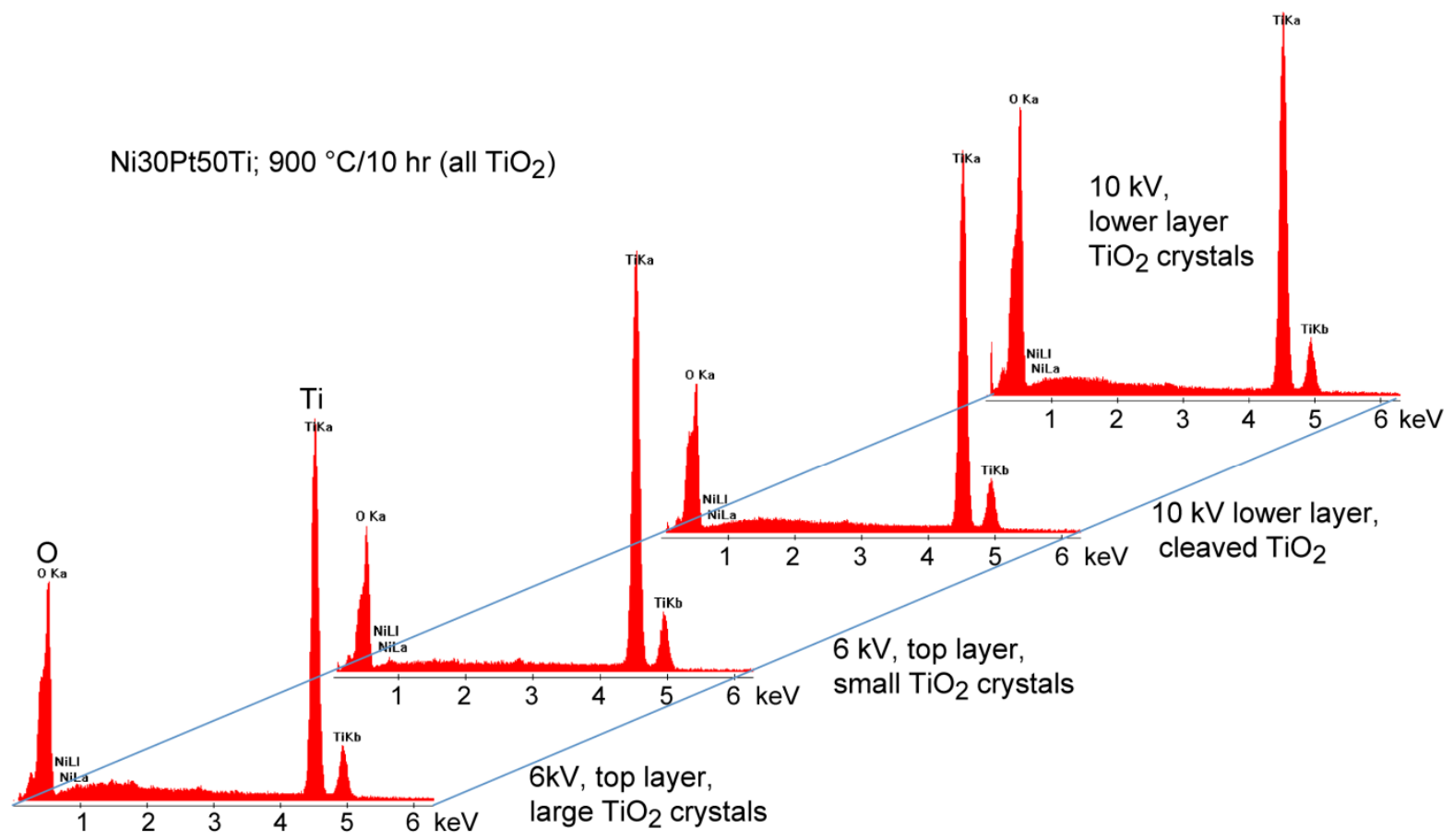

Figure 33.-SEM/EDS spectra showing similar Ti-O profiles for outer large or fine grain scales and lower cleaved or striated grains (Ni30Pt50Ti after $10 \mathrm{hr}$ oxidation at $900{ }^{\circ} \mathrm{C}$ ).

\section{Discussion}

The above confirms that a commercial NiTi and an experimental $\mathrm{Ni}(\mathrm{Pt}) \mathrm{Ti}$ shape memory alloy form primarily fast-growing $\mathrm{TiO}_{2}$ rutile scales over a wide temperature range and after relatively long-term exposure. Thus the report of activation energies $(250 \mathrm{~kJ} / \mathrm{mole} \mathrm{K})$ near that reported for other Ni-Ti studies exhibiting rutile as the primary scale phase is not unexpected. The $\mathrm{TiO}_{2}$ anatase phase may have been present as a trace for the NiTi alloy at low temperature. $\mathrm{NiTiO}_{3}$ formed as secondary oxides on both alloys, reaching a maximum on the order of 25 percent. This oxide phase was difficult to distinguish microstructurally in cross-section and often appeared as small dispersed particles in plan SEM. NiO was also somewhat elusive microstructually. As demonstrated by serial and taper-section XRD and by SEM in plan and cross-sections, it was present only as a minor phase $<20$ percent, appeared to predominate at the gas surface and only for the NiPtTi alloy. Proceeding inward, dispersed metallic Ni(Ti) and Pt(Ni) solid solution particles were observed on the NiTi and NiPtTi alloys, respectively. Finally, metallic depletion zones are encountered, first as fingerlike protrusions into the scale, then as a continuous layer of predominantly $\mathrm{Ni}_{3} \mathrm{Ti}$ or $\mathrm{Pt}_{3} \mathrm{Ti}$, with some oxygen in solid solution. The NiPtTi substrate also appeared to have thermally-aged into a mixture of the $\mathrm{B} 19 \mathrm{Pt}(\mathrm{Ni}) \mathrm{Ti}$ martensitic phase and a new hexagonal structure of similar composition, perhaps a new martensitic variant or grain boundary-decomposition phase. $\mathrm{The} \mathrm{Fe}_{3} \mathrm{O}_{4}$ and $\mathrm{TiC}$ were identified as artifacts from unintentional processing impurities, such as melting in graphite crucibles, and are believed to have been relatively innocuous to the primary oxidation process.

Most of the scale features identified on the NiTi alloy have been observed to various degrees and under various conditions in the literature. The serial-sectioning XRD study by Satow et al. (Ref. 2) catalogued the transition from a pure rutile external scale, to a mixture with $\mathrm{NiTiO}_{3}$, to a $\mathrm{Ni}$ then $\mathrm{Ni}_{3} \mathrm{Ti}$ depletion zone, and finally the NiTi substrate. Others observed the anatase structure sporadically, primarily for lower temperature and shorter time exposures. Porosity was more prevalent in some studies, and spalling was occasionally observed. Dispersed metallic particles and depletion zones sometimes took the form of various $\mathrm{Ni}_{\mathrm{x}} \mathrm{Ti}_{\mathrm{y}}$ stoichiometry. A NiPdTi alloy exhibited some reduction in growth rate as did the NiPtTi here. 
It has been mentioned that the NiPtTi ternary alloy oxidized with parabolic kinetics about four times lower than that of the binary NiTi alloy. Since the oxide phases were quite similar on both alloys, the difference cannot be explained by modifications in the scale growth and diffusivity. However the existence of a continuous $\mathrm{Pt}_{3} \mathrm{Ti}$ depletion zone may serve to restrict Ti outward diffusion from the substrate, as compared to an $\mathrm{Ni}_{3} \mathrm{Ti}$ zone for the binary alloy. Associated with this feature, the dispersion of metallic particles in the scale appear as solvent remnants from the oxidation of $\mathrm{Ti}$ "solute" constituent. In the case of the NiTi binary, this phase appears as a fine dispersion in the inner layer of a duplex $\mathrm{TiO}_{2}$ scale, trending toward the $\mathrm{Ni}_{3} \mathrm{Ti}$ metallic fingers and the depeletion zone. For the NiPtTi alloy, a $13-\mu \mathrm{m}$ mixed cermet zone of $\mathrm{Pt}(\mathrm{Ni})+\mathrm{TiO}_{2}$ inner scale trended toward $\mathrm{Pt}_{3} \mathrm{Ti}$ fingers and depletion zone. The noble inert Pt phase can thus be viewed as a partial diffusion barrier retarding the outward transport of Ti toward the oxidative interface (or retarding the inward transport of oxygen).

One of the more unusual features of these scales is the presence of dispersed, unoxidized Ni particles embedded in $\mathrm{TiO}_{2}$ matrix. These presumably were metallic remnants of the NiTi substrate after the Ti was completely depleted by selective oxidation. The fact that they were not oxidized perhaps indicates that the local $\mathrm{pO}_{2}$ is below that needed to oxidize Ni. Another possibility is that the growth of $\mathrm{TiO}_{2}$ is very rapid in comparison to $\mathrm{NiO}$ growth (about $10 \mathrm{x}$ on average $\mathrm{k}_{\mathrm{p}}$ increase (Ref. 2)). Thus, Ti is extracted out of the alloy, leaving $\mathrm{Ni}$ in a metastable metallic state, only gradually being converted to $\mathrm{NiTiO}_{3}$. The fact that relatively little $\mathrm{NiTiO}_{3}$ and metallic $\mathrm{Ni}$ are found in the scale suggests that the primary steady state growth mechanism is outward transport of Ti, leaving Ni-rich phases behind as depleted layers. However the concentration of $\mathrm{NiTiO}_{3}$ in the outer layers suggests an initial transient oxidation product and inward new growth by oxygen diffusion. Internal oxidation and breakup of the metallic diffusion zone found in more dilute alloys is similar to the finger structure of the depletion zones here and the isolation of individual particles in the scale. Since Ti is well known for its affinity for oxygen in solution, it is not surprising to find some manifestation of its internal oxidation tendencies here.

It is also interesting to compare the above features to those observed for Ni-5,10,15Ti alloys (Ref. 14). Here more distinct layers were formed, with $\mathrm{NiO}$ at the gas surface, followed by an $\mathrm{NiTiO}_{3}$ layer, then internal fingers of $\mathrm{TiO}_{2}$. Ti-depletion zones were formed beneath the scale similar to the NiTi SMAs. The kinetics were analyzed to be somewhat between those of pure Ni and NiTi SMA alloys (Ref. 2).

Given the rich, detailed structures described above, perhaps the most obvious structural feature is the most striking, that of striated, faceted external $\mathrm{TiO}_{2}$ crystals. These are seen to enlarge quite dramatically with oxidation temperature. Such external growth features suggest some component of outward $\mathrm{Ti}$ diffusion. A summary figure of the average crystal width is given in Figure 34, suggesting a type of Arrhenius relation based on a thermally-activated process. Note that the scale grains are approximately equal for both Ni49Ti and Ni-30Pt-50Ti alloys, even though the scale thickness growth rates were faster for the binary alloy. Also, note that the ternary alloy possessed a more prominent fine-grain base scale (dashed curve) that was approximately seven times smaller than the larger grain outcroppings.

This figure also compares the grain size found for $\mathrm{TiO}_{2}$ scales on other NiTi and Ti alloys. Again, Arrhenius-type relations are suggested, but for considerably smaller sizes. This difference is primarily due to the long times used here $(100 \mathrm{hr})$ compared to those in the literature (4 hr, Vojtêch et al. and Xu et al. (Refs. 8 and 9); 1 to $2 \mathrm{hr}$, Park (Ref. 15)). Vojtech et al. attempted to determine an activation energy by estimating scale growth kinetic constants, albeit from limited time data, assuming a $\mathrm{t}^{1 / 3}$ kinetic law. They determined that to be $45 \mathrm{~kJ} / \mathrm{mole}$, or about $1 / 3$ that of the oxidation kinetics, as reflected in the shallow slope of their curve in Figure 34. No kinetic grain growth rates were determined in the present study. 


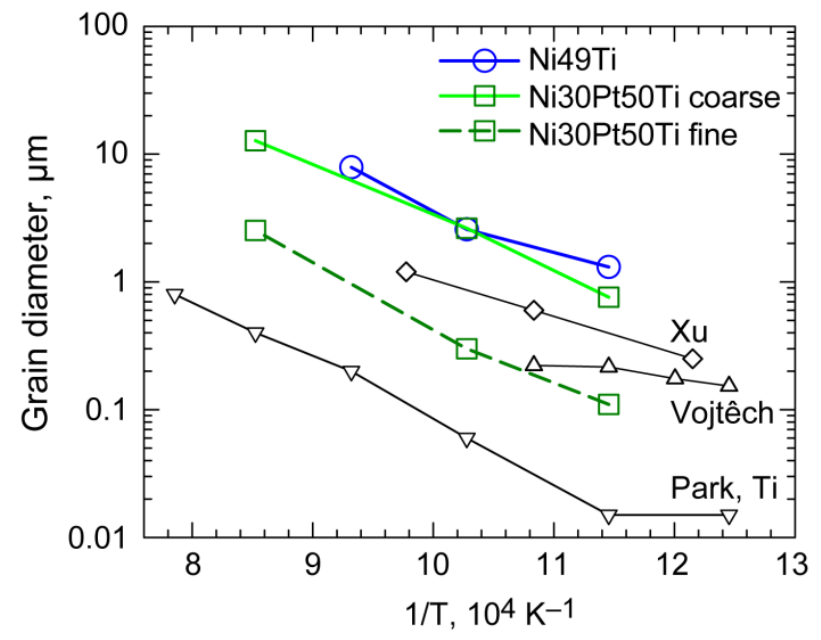

Figure 34.-Temperature effects on increased grain size: $\mathrm{TiO}_{2}$ scales formed in this study compared to literature values (Refs. 7,8 , and 15).

\section{Summary}

Ni49Ti and Ni-30Pt-50Ti shape memory alloys have been isothermally-oxidized in air at 500 to $900{ }^{\circ} \mathrm{C}$. The scales were characterized by SEM/EDS and XRD in plan, cross-section, and serial or tapered sections. $\mathrm{TiO}_{2}$ rutile phases dominated the scale make-up, with distinct striated and faceted external grain structure. The grain size was found to be highly temperature dependent and similar for each alloy, but more uniform on the binary alloy and duplex on the ternary. The NiPtTi alloy exhibited many features in common with the NiTi alloy, but at about $1 / 2$ the overall scale thickness, as expected from the previous thermogravimetric kinetic study. $\mathrm{NiTiO}_{3}$ was also found, primarily for NiPtTi and in outer layers of the scale, but in amounts less than that expected for complete alloy oxidation. The excess Ni appeared to concentrate in dispersed metallic particles or in the $\mathrm{Ni}_{3} \mathrm{Ti}$ and $(\mathrm{Pt}, \mathrm{Ni})_{3} \mathrm{Ti}$ depletion zones. It is believed that the dispersed $\mathrm{Pt}(\mathrm{Ni}, \mathrm{Ti})$ particulate and continuous $(\mathrm{Pt}, \mathrm{Ni})_{3} \mathrm{Ti}$ depletion zone contributes to a reduced oxidation rate by limiting outward diffusion of Ti compared to alloys without Pt. In addition, a previously unreported hexagonal phase with the $\mathrm{Ni}_{3} \mathrm{Sn}$ structure $\left(\mathrm{D}_{19}\right)$ was observed in the Ni-30Pt-50Ti samples oxidized (aged) at $700{ }^{\circ} \mathrm{C}$.

\section{References}

1. R. Noebe, D. Gaydosh, S. Padula, A. Garg, T. Biles, and M. Nathal, "Properties and Potential of Two (Ni,Pt)Ti Alloys for Use as High-Temperature Actuator Materials," in Smart Structures and Materials 2005: Active Materials: Behavior and Mechanics, SPIE Conf. Proc. vol. 5761, (2005), pp. 364-375.

2. J.L. Smialek, D.L. Humphrey, and R.D. Noebe, "Comparative Oxidation Kinetics of a High Temperature NiPtTi Shape Memory Alloy," Oxidation of Metals, 74, No. 3 (2010), pp. 125-144.

3. T. Satow, T. Isano, and T. Honma, "The High Temperature Oxidation of Intermetallic Compound NiTi," Journal of the Japan Institute of Metals, 38 (1974) 242-246.

4. C.M. Chan, S. Trigwell, T.W. Duerig, "Oxidation of an NiTi Alloy," Surface and Interface Analysis, 5, pp. 349-354 (1990).

5. C.L. Chu, S.K. Wu, Y.C. Yen, "Oxidation behavior of equiatomic TiNi alloy in high temperature air environment," Materials Science and Engineering, A 216, pp. 193-200 (1996).

6. G.S. Firstov, et al., "Surface oxidation of NiTi shape memory alloy," Biomaterials, 23, pp. 48634871 (2002). 
7. L. Zhu, J.M. Fino, and A. Pelton, "Oxidation of Nitinol," in SMST-2003, Proceedings of the International Conference on Shape Memory and Superplastic Technologies, eds. T.W. Duerig and A. Pelton, SMST-ASM International, Metals Park, OH (2003).

8. D. Vojtěch, P. Novák, M. Novák, L. Jaska, T. Fabián, J. Maixner, and V. Machovič, "Cyclic and isothermal oxidation of nitinol wire at moderate temperatures," Intermetallics, 16 (2008) 424-431.

9. C.H. Xu, X.Q. Ma, S.Q. Shi, C.H. Woo, "Oxidation behavior of TiNi shape memory alloy at 450 $750{ }^{\circ} \mathrm{C}$," Materials Science and Engineering, A 371, pp. 45-50 (2004).

10. Q. Tian and J. Wu, "Effect of the Rare Earth Element Ce on Oxidation Behavior of TiPdNi Alloys," Materials Science Forum, 394-395, pp. 455-458 (2002).

11. Q. Tian, J. Chen, Y. Chen, and J. Wu, "Oxidation behavior of TiNi-Pd shape memory alloys," Z. Metallkde., 94, pp. 36-40 (2003).

12. K-N. Lin and S-K Wu, "Oxidation Behavior of Ti50Ni40Cu10 Shape-Memory Alloy in 700$1000{ }^{\circ} \mathrm{C}$ Air," Oxidation of Metals, 71 (2009) 187-200.

13. J.L. Smialek, D.L. Humphrey, and R.D. Noebe, "Oxidation Kinetics of a NiPtTi High Temperature Shape Memory Alloy,” NASA/TM-2007-214697, NASA, Washington, DC.

14. C.L. Zeng, M.C. Li, G.Q. Liu, and W.T. Wu, "Air Oxidation of Ni-Ti Alloys at $650-850{ }^{\circ} \mathrm{C}$," Oxidation of Metals, 58 (2002) 171-184.

15. Y-J. Park, H-J. Song, I. Kim, H-S. Yang, "Surface characteristics and bioactivity of oxide film on titanium metal formed by thermal oxidation," J. Mater. Med., 18 (2007) 565-575. 


\section{Bibliography}

Atkinson, A.; Taylor R.I.; and Hughes A.E. (1982): A Quantitative Demonstration of the Grain Boundary Diffusion Mechanism for the Oxidation of Metals. Phil. Mag., vol. A45, pp. 823-833.

DeCastro, J.A.; Melcher, K.J.; and Noebe, R.D. (2005): System-Level Design of a Shape Memory Alloy Actuator for Active Clearance Control in the High-Pressure Turbine. AIAA-2005-3988.

Gulbransen, E.A.; and Andrew, K.F. (1954): The Kinetics of Oxidation of High Purity Nickel. J. Electrochem. Soc., vol. 128, pp. 121-140.

Kofstad, P. (1988): High Temperature Corrosion. Elsevier Applied Science, London, pp. 212 and 293.

Lindquist, P.G.; and Wayman C.M. (1990): Shape Memory and Transformation Behavior of Martensitic Ti-Pd-Ni and Ti-Pt-Ni Alloys. Engineering Aspects of Shape-Memory Alloys, T.W. Duerig et al., eds., Butterworth-Heinemann, London, pp. 58-68.

Noebe, R.D.; Biles, T.; and Padula, S.A. (2006): Chapter 7: NiTi-Based High-Temperature ShapeMemory Alloys: Properties, Prospects, and Potential Applications. Advanced Structural Materials: Properties, Design Optimization, and Applications, W.O. Soboyejo, ed., Taylor \& Francis Group, Boca Raton, FL, pp. 141-180.

Noebe, R., et al. (2006): Effect of Thermomechanical Processing on the Microstructure, Properties, and Work Behavior of a $\mathrm{Ti}_{50.5} \mathrm{Ni}_{29.5} \mathrm{Pt}_{20}$ High-Temperature Shape Memory Alloy. SMST 2006:

Proceedings of the International Conference on Shape Memory and Superelastic Technologies, ASM International, Metals Park, OH, pp. 409-426.

Otsuka, K.; and Wayman, C.M., eds. (1998): Shape Memory Materials. Cambridge University Press, Cambridge, U.K.

Pieraggi, B. (1987): Calculations of Parabolic Reaction Rate Constants. Oxid. Met., vol. 27, pp. 177-185.

Progar, D.J.; and Lewis, B.W.: A Study of Oxidation Kinetics of Nickel Metal in Flowing Air and Oxygen-Nitrogen Mixtures. NASA TN-D-2224, 1964.

Rios, O., et al. (2005): Characterization of Ternary NiTiPt High-Temperature Shape Memory Alloys. Smart Structures and Materials 2005: Active Materials: Behavior and Mechanics, SPIE Conference Proceedings, vol. 5761, pp. 376-387.

Smialek, J.L.; and Humphrey, D.L. (1992): Oxidation Kinetics of Cast TiAl ${ }_{3}$. Scripta Metall. Mater., vol. 26, pp. 1763-1768. 


\begin{tabular}{|c|c|c|}
\hline \multicolumn{2}{|c|}{ REPORT DOCUMENTATION PAGE } & $\begin{array}{l}\text { Form Approved } \\
\text { OMB No. 0704-0188 }\end{array}$ \\
\hline \multicolumn{3}{|c|}{ 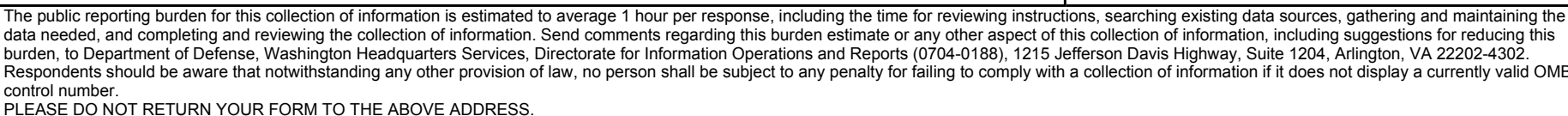 } \\
\hline $\begin{array}{l}\text { 1. REPORT DATE (DD-MM-YYYY) } \\
01-09-2011\end{array}$ & $\begin{array}{l}\text { 2. REPORT TYPE } \\
\text { Technical Memorandum }\end{array}$ & 3. DATES COVERED (From - To) \\
\hline \multirow{3}{*}{\multicolumn{2}{|c|}{$\begin{array}{l}\text { 4. TITLE AND SUBTITLE } \\
\text { Oxide Scales Formed on NiTi and NiPtTi Shape Memory Alloys }\end{array}$}} & 5a. CONTRACT NUMBER \\
\hline & & 5b. GRANT NUMBER \\
\hline & & 5c. PROGRAM ELEMENT NUMBER \\
\hline \multirow{3}{*}{\multicolumn{2}{|c|}{$\begin{array}{l}\text { 6. AUTHOR(S) } \\
\text { Smialek, James, L.; Garg, Anita; Rogers, Richard, B.; Noebe, Ronald, D. }\end{array}$}} & 5d. PROJECT NUMBER \\
\hline & & 5e. TASK NUMBER \\
\hline & & $\begin{array}{l}\text { 5f. WORK UNIT NUMBER } \\
\text { WBS 984754.02.07.03.16.04 }\end{array}$ \\
\hline \multicolumn{2}{|c|}{$\begin{array}{l}\text { 7. PERFORMING ORGANIZATION NAME(S) AND ADDRESS(ES) } \\
\text { National Aeronautics and Space Administration } \\
\text { John H. Glenn Research Center at Lewis Field } \\
\text { Cleveland, Ohio 44135-3191 }\end{array}$} & $\begin{array}{l}\text { 8. PERFORMING ORGANIZATION } \\
\text { REPORT NUMBER } \\
\text { E- } 17748\end{array}$ \\
\hline \multirow{2}{*}{\multicolumn{2}{|c|}{$\begin{array}{l}\text { 9. SPONSORING/MONITORING AGENCY NAME(S) AND ADDRESS(ES) } \\
\text { National Aeronautics and Space Administration } \\
\text { Washington, DC 20546-0001 }\end{array}$}} & $\begin{array}{l}\text { 10. SPONSORING/MONITOR'S } \\
\text { ACRONYM(S) } \\
\text { NASA }\end{array}$ \\
\hline & & $\begin{array}{l}\text { 11. SPONSORING/MONITORING } \\
\text { REPORT NUMBER } \\
\text { NASA/TM-2011-217096 }\end{array}$ \\
\hline \multicolumn{3}{|c|}{$\begin{array}{l}\text { 12. DISTRIBUTION/AVAILABILITY STATEMENT } \\
\text { Unclassified-Unlimited } \\
\text { Subject Category: } 26 \\
\text { Available electronically at http://www.sti.nasa.gov } \\
\text { This publication is available from the NASA Center for AeroSpace Information, 443-757-5802 }\end{array}$} \\
\hline
\end{tabular}

\section{SUPPLEMENTARY NOTES}

\section{ABSTRACT}

$\mathrm{Ni}-49 \mathrm{Ti}$ and Ni-30Pt-50Ti (at.\%) shape memory alloys were oxidized isothermally in air over the temperature range of 500 to $900{ }^{\circ} \mathrm{C}$. The microstructure, composition, and phase content of the scales were studied by SEM, EDS, XRD, and metallography. Extensive plan view $\mathrm{SEM} / \mathrm{EDS}$ identified various features of intact or spalled scale surfaces. The outer surface of the scale was a relatively pure $\mathrm{TiO}_{2}$ rutile structure, typified by a distinct highly striated and faceted crystal morphology. Crystal size increased significantly with temperature. Spalled regions exhibited some porosity and less distinct features. More detailed information was obtained by correlation of SEM/EDS studies of $700{ }^{\circ} \mathrm{C} / 100 \mathrm{hr}$ cross-sections with XRD analyses of serial or taper-polishing of plan surfaces. Overall, multiple layers exhibited graded mixtures of $\mathrm{NiO}, \mathrm{TiO}_{2}, \mathrm{NiTiO}_{3}, \mathrm{Ni}(\mathrm{Ti})$ or $\mathrm{Pt}(\mathrm{Ni}, \mathrm{Ti})$ metal dispersoids, $\mathrm{Ni}_{3} \mathrm{Ti}_{\text {or }} \mathrm{Pt}_{3} \mathrm{Ti}_{\text {depletion zones, and substrate, in that order. The } \mathrm{NiTi}}$ alloy contained a 3 at.\% Fe impurity that appeared in embedded localized Fe-Ti-rich oxides, while the NiPtTi alloy contained a 2 v/o dispersion of $\mathrm{TiC}$ that appeared in lower layers. The oxidation kinetics of both alloys (in a previous report) indicated parabolic growth and an activation energy $(250 \mathrm{~kJ} / \mathrm{mole})$ near those reported in other $\mathrm{Ti}$ and $\mathrm{NiTi}$ studies. This is generally consistent with $\mathrm{TiO}_{2}$ existing as the primary scale constituent, as described here.

\section{SUBJECT TERMS}

Nitinol alloys; Oxidation; Scale (corrosion)

\begin{tabular}{|c|c|c|c|c|c|}
\hline \multicolumn{3}{|c|}{ 16. SECURITY CLASSIFICATION OF: } & \multirow{2}{*}{$\begin{array}{l}\text { 17. LIMITATION OF } \\
\text { ABSTRACT } \\
\text { UU }\end{array}$} & \multirow{2}{*}{$\begin{array}{l}\text { 18. NUMBER } \\
\text { OF } \\
\text { PAGES } \\
36\end{array}$} & \multirow{2}{*}{$\begin{array}{l}\text { 19a. NAME OF RESPONSIBLE PERSON } \\
\text { STI Help Desk (email:help@sti.nasa.gov) } \\
\text { 19b. TELEPHONE NUMBER (include area code) } \\
\text { 443-757-5802 }\end{array}$} \\
\hline $\begin{array}{l}\text { a. REPORT } \\
\text { U }\end{array}$ & $\begin{array}{l}\text { b. ABSTRACT } \\
U\end{array}$ & $\begin{array}{l}\text { c. THIS } \\
\text { PAGE } \\
\text { U }\end{array}$ & & & \\
\hline
\end{tabular}



